University of Wollongong

Research Online

Australian Institute for Innovative Materials -

Papers

Australian Institute for Innovative Materials

$1-1-2019$

Fabrication of nitrogen and sulfur co-doped carbon nanofibers with threedimensional architecture for high performance supercapacitors

Wen Lei

Wuhan University of Science and Technology

Haijun Zhang

Wuhan University of Science and Technology

Dezheng Liu

Hubei University of Arts and Science

Liangxu Lin

University of Wollongong, Wuhan University of Science and Technology, liangxu@uow.edu.au

Follow this and additional works at: https://ro.uow.edu.au/aiimpapers

Part of the Engineering Commons, and the Physical Sciences and Mathematics Commons

Research Online is the open access institutional repository for the University of Wollongong. For further information contact the UOW Library: research-pubs@uow.edu.au 


\title{
Fabrication of nitrogen and sulfur co-doped carbon nanofibers with three- dimensional architecture for high performance supercapacitors
}

\author{
Abstract \\ Making full use of the high water-holding capability of bacterial cellulose, a highly N/S dual-doped carbon \\ fibers (NSCF) with interconnected three dimensional structure is prepared by an absorption-swelling \\ strategy. Supercapacitor electrode fabricated from this material delivers a high specific capacitance of \\ $202 \mathrm{~F} \mathrm{~g}-1$, which is two times higher than that of the pristine un-doped one at current density of $1.0 \mathrm{~A}$ \\ g-1. This dual-doped NSCF shows good wettability, fast ion-transportation and desirable electrical \\ conductivity, which are indispensable characters of an electrode material in building the supercapacitor \\ with desired high power performances. \\ Disciplines \\ Engineering | Physical Sciences and Mathematics

\section{Publication Details} \\ Lei, W., Zhang, H., Liu, D. \& Lin, L. (2019). Fabrication of nitrogen and sulfur co-doped carbon nanofibers \\ with three-dimensional architecture for high performance supercapacitors. Applied Surface Science, 495 \\ 143572-1-143572-8.
}




\section{Highlights}

N/S co-doped carbon nanofibers (NSCF) was prepared by a concise and eco-friendly way

NSCF shows superiorities in wettability, ion-transport and electrical conductivity

- N/S dual-doping is proved to improve the capacitance behaviors 


\section{Fabrication of Nitrogen and Sulfur Co-Doped Carbon} Nanofibers with Three-Dimensional Architecture for High

\section{Performance Supercapacitors}

Wen Lei ${ }^{a}$, Haijun Zhang ${ }^{a}$, Dezheng Liu, ${ }^{b *}$ and Liangxu Lin ${ }^{a, c^{*}}$

${ }^{a}$ The State Key Laboratory of Refractories and Metallurgy, and Institute of Advanced Materials and Nanotechnology, Wuhan University of Science and Technology, Wuhan, 430081, China

${ }^{b}$ Department of Mechanical Engineering, Hubei University of Arts and Science, Xiangyang, Hubei 441053, China

${ }^{\mathrm{c}}$ ARC Centre of Excellence for Electromaterials Science, Intelligent Polymer Research Institute, Australia Institute of Innovative Materials (AIIM), Innovation Campus, University of Wollongong, Wollongong 2500, Australia

Abstract: Making full use of the high water-holding capability of bacterial cellulose, a highly N/S dual-doped carbon fibers (NSCF) with interconnected three dimensional structure is prepared by an absorption-swelling strategy. Supercapacitor electrode fabricated from this material delivers a high specific capacitance of $202 \mathrm{~F} \mathrm{~g}^{-1}$, which is two times higher than that of the pristine un-doped one at current density of $1.0 \mathrm{~A}$ $\mathrm{g}^{-1}$. This dual-doped NSCF shows good wettability, fast ion-transportation and desirable electrical conductivity, which are indispensable characters of an electrode material in building the supercapacitor with desired high power performances.

Keywords: Bacterial cellulose; three dimensional; N/S co-doping; supercapacitors

\section{Introduction}

Owing to their multitudinous structural, morphological and chemical properties, carbon materials have found good applications in different fields, particularly as electrode material of supercapacitors [1]. Such carbon materials should be appropriately modified to satisfy the increasing demand on the high energy and power performances of nowadays energy storage devices [2].

So far, numerous reports have verified the positive effects of heteroatoms

*Corresponding author. E-mail: liudezheng@ @buas.edu.cn. Tel.: (+86) 0710-3592271.

${ }^{*}$ Corresponding author. E-mail: L.Lin@wust.edu.cn. Tel.: (+86) 027-68862825. 
doping on the electrochemical property enhancement of carbon materials, and put forward the following mechanisms: 1) the improvement of electrode wettability owing to the increased hydrophilic polar sites [3];2) the enhancement in electrical conductivity owing to the newly introduced charge carrier at the conduction band [4]; 3) the occurrence of space-charge-layer capacitance by increasing its electron density [5] and 4) the appearance of pseudo-capacitance derived from the surface faradaic reaction because of the electronegativity difference between the carbon and the incorporated heteroatoms [6]. Till now, several methods, including the in-situ doping strategy and post-processing treatment, have been attempted to introduce heteroatoms into the carbon framework [7]. The in-situ doping strategy normally involves a direct carbonization process of heteroatoms containing carbonaceous materials (e.g. biomass materials [8] and organic compounds [9]). As for the post-processing treatment, carbon materials are normally mixed and reacted with the functional dopant (e.g. ammonia gas, urea and boric acid) under appropriate heat treatment [7]. Even so, the improvement in the capacitance behaviors was still limited due to the low content of the dopant. In this regard, the dual-heteroatoms doping strategy was proposed to further improve the capacitance. Besides the benefit from the synergistic effects between different dopants, such a strategy can also improve the ratio of dopants.

For instance, N/S co-doped graphene [10], B/N co-doped carbon material [11] and N/P co-doped graphene [12] have been prepared with energy storage capacitance superior to their undoped and single element doping counterparts. Among diversified doping forms mentioned above, N/S co-doping has been considered more promising owing to the significant changes in spin density, the polarisability as well as the structural defects caused by the bigger diameter of sulfur's atom [13]. However, the state of the art strategies for preparing N/S co-doped carbon materials are always complicated, as it also largely involves different features (e.g. size, morphology, porous structure) of various raw materials. Different approaches have been made in this regard [14, 15], but how to concisely fabricate the heteroatom-doped carbon material with rational designed structure and 
high heteroatoms doping content at a low-cost level is still a challenge.

In this work, we put forward a concise and efficient alternative choice to produce nitrogen and sulfur co-doped carbon nanofibers (NSCF) from the bacterial cellulose (BC). As the masterpiece of nature's art, BC has many interesting features such as the ultrafine three-dimensional (3D) network, excellent biodegradability and biocompatibility [16] [17] [18], giving significant inherent advantages in severing as the precursor for porous carbon structure [19]. The loose arrangement of nanofibers, the high specific surface area and the hydrophilic nature of BC endow an ultra-high water holding capacity (> 200 times of its dry weight), making it an ideal platform of holding dopants with high ratio [20] [21]. Starting from the simple strategy of adsorption and swelling, the thin BC pellicle (never-dried) was used to absorb the saturated thiourea solution and then transformed to the NSCF which possess many favorable properties (e.g. high wettability, high electrical conductivity and robust 3D architecture) for supercapacitors. By way of example, we demonstrate a capacitance of $202 \mathrm{~F} \mathrm{~g} \mathrm{~g}^{-1}$ at the current density of $1.0 \mathrm{~A} \mathrm{~g}^{-1}$, and a long-term cycling performance up to 5000 cycles without obvious capacitance fading.

\section{Experimental section}

2.1 Pretreatment of $\mathrm{BC}$ : $\mathrm{BC}$ membrane, kindly provided by Prof. Chonghua Pei (School of Materials Science and Engineering, Southwest University of Science and Technology), was immersed into a solution of $0.10 \mathrm{M} \mathrm{NaOH}$ at $50{ }^{\circ} \mathrm{C}$ for $2 \mathrm{~h}$ to remove bacteria and residues, and then thoroughly washed with distilled water until $\mathrm{pH}$ is close to 7 .

2.2 Preparation of NSCF: The gel-like pre-treated BC pellicle was pressed under a $10 \mathrm{~kg}$ stainless steel plate for $10 \mathrm{~h}$ to remove the holding water and then cut into rectangular pieces sized $2 \times 2 \mathrm{~cm}$ (make sure the membrane still contains moisture). Afterwards, the obtained thin $\mathrm{BC}$ piece (defined as never-dried $\mathrm{BC}$ membrane) was immersed into a saturated thiourea aqueous solution for $48 \mathrm{~h}$ until it fully swelled to its normal shape. The swelled piece was then frozen in liquid nitrogen and immediately placed in a freezer drier (sublimating temperature of $-55^{\circ} \mathrm{C}$, pressure of $0.015 \mathrm{mbar}$ ) for $48 \mathrm{~h}$ to remove water. The as-obtained $\mathrm{BC}$ thiourea lump was then 
directly calcined under Ar atmosphere protection with a set temperature programming $\left(2.0{ }^{\circ} \mathrm{C} \mathrm{min}{ }^{-1}\right.$ to $500{ }^{\circ} \mathrm{C}$ for $1.0 \mathrm{~h}$ and then at $5.0^{\circ} \mathrm{C} \mathrm{min}{ }^{-1}$ to $850{ }^{\circ} \mathrm{C}$ for $2.0 \mathrm{~h}$ ). Finally, the black product was obtained. As a control, the undoped carbonized BC, namely $\mathrm{CBC}$, was prepared by direct carbonization of the freeze-dried $\mathrm{BC}$ membrane at the identical temperature programming.

\subsection{Material characterization}

Scanning transmission electron microscopy (S-TEM) and TEM images were obtained on STEM (Tecnai G2 F30). Elemental mapping were conducted using EDAX detector attached on Tecnai G2 F30. Thermal gravimetric analysis (TGA) was conducted on Pyris1 TGA Instrument at $30-800{ }^{\circ} \mathrm{C}$ in a $10 \mathrm{~mL} \mathrm{~min}^{-1} \mathrm{~N}_{2}$ flow with a heating rate of $10{ }^{\circ} \mathrm{C} \mathrm{min}^{-1}$. X-ray photoelectron spectroscopic (XPS) were collected on an AXIS-ULTRA DLD-600W Instrument. FTIR measurements were conducted on a Bruker Vector-22 FTIR spectrometer at $4000-500 \mathrm{~cm}^{-1}$. Raman spectra were taken by a LabRam HR800 spectrometer with a $532 \mathrm{~nm}$ laser excitation. The electronic conductivities were studied by the four-probe method with a ST-2258C multifunction digital four-probe tester.

$\mathrm{N}_{2}$ sorption analysis was carried out on an ASAP 2020 accelerated surface area and porosimetry instrument (Micromeritics), equipped with an automated surface area, at $77 \mathrm{~K}$ using Barrett-Emmett-Teller (BET) calculations for the surface area. The pore size distribution (PSD) plot was produced with the adsorption branch of the isotherm based on the Barrett-Joyner-Halenda (BJH) model. The CHN analysis was carried out using an Elementarvario EL cube.

\subsection{Electrochemical tests}

6.0 $\mathrm{M} \mathrm{KOH}$ solution was used as electrolyte in all experiments at room temperature. The working electrode was prepared by taking active material, conductive additive (acetylene black), and binder (PTFE) in the weight ratio (80:10:10) and mixed together with ethanol to obtain the slurry. The mass load of each electrode is about 3.0 $\mathrm{mg} \mathrm{cm}{ }^{-2}$. For three-electrode test: All electrochemical measurements were carried out by using platinum sheet as counter electrode, as-prepared electrode as working electrode referred to $\mathrm{Ag} / \mathrm{AgCl}$ reference electrode. For two-electrode test, the 
as-prepared electrodes were assembled to the symmetric cell in a 2032-type coin cell. Cyclic voltammetry (CV), electrochemical impedance spectroscopy (EIS) and galvanostatic charge/discharge (GCD) tests were all performed with $\mathrm{CHI} 760 \mathrm{e}$ electrochemical workstation ( $\mathrm{CH}$ Instruments, China). $\mathrm{CV}$ and $\mathrm{GCD}$ tests were performed between -1.0 and $0 \mathrm{~V}$. The specific capacitance was calculated based on the equation $\mathrm{C}_{\mathrm{s}}=\mathrm{It} / \mathrm{m} \Delta \mathrm{V}$. EIS tests were performed at open-circuit potential in the frequency range from $100 \mathrm{kHz}$ to $0.01 \mathrm{~Hz}$ with an $\mathrm{AC}$ perturbation of $5 \mathrm{mV}$.

\section{Results}

As illustrated in Figure 1, the NSCF was prepared through a facial two-step doping procedure. The pre-treated never-dried thin $\mathrm{BC}$ pellicle with a thickness of 0.1 $\mathrm{cm}$, was immersed in the saturated thiourea aqueous solution until it reached the swelling equilibrium state after $48 \mathrm{~h}$ (Figure 1a). The obtained swelled BC pellicle was treated with liquid nitrogen and then freeze-dried to remove water (Digital photograph of dried BC lump is shown in Figure S1). Since BC has already a high initial level of inter-fiber bonding through extensive hydrogen bonding of continuous nano-ribbons, $\mathrm{N}-\mathrm{H}$ groups of thiourea were supposed to form multitopic hydrogen bonds with the hydroxyl group of BC (Figure 1b). Therefore, during the high temperature treatment, $\mathrm{N}$ and $\mathrm{S}$ contained functionalities from thiourea could be covalently attached onto the $\mathrm{BC}$ or $\mathrm{BC}$ derived carbon, and were then incorporated into the carbon framework [22].

According to the thermogravimetric analyzer (TGA) result (in $\mathrm{N}_{2}$ atmosphere), the thermosol temperature of thiourea is around $200{ }^{\circ} \mathrm{C}$ (Figure 2a). During this period, the isomerization of thiourea could be observed. Along with the temperature increases, some gases (e.g. $\mathrm{NH}_{3}, \mathrm{H}_{2} \mathrm{~S}, \mathrm{SO}_{\mathrm{x}}$ ) would be released and attached on the surface of $\mathrm{BC}$ [23]. After the calcination, the X-ray diffraction (XRD) pattern of the CBC shows a diffraction peak at $25.8^{\circ}$, while NSCF exhibits a broader peak at $23.7^{\circ}$, suggesting a much larger interlayer spacing induced by the N/S co-doping (Figure 2b). The broadened full width at half maximum and the significantly decreased intensity of the NSCF imply a much lower graphitization degree owing to the N/S co-doping [24].

Scanning electron microscope (SEM) and transmission electron microscope 
(TEM) characterizations were then performed to investigate the morphology of samples. As shown as the SEM image (Figure S2a), the pristine BC presents an interconnected 3D nanofibrous structure with the fiber diameter of about $30 \mathrm{~nm}$ and a length ranging from micrometers to dozens of micrometers. This unique 3D interwoven structure contains numerous - $\mathrm{OH}$ groups, which can act as bridging ligands for assembling nanoscaled building units to control the desired morphology. Moreover, the 3D network-like structure is favorable for increasing the effective reaction surface and facilitates its combination to thiourea. The obtained CBC inherited the morphology of $\mathrm{BC}$ after the calcination at $850^{\circ} \mathrm{C}$ (Figure S2b). Similarly, NSCF shows exactly the same nanofibrous morphology as that of CBC (Figure S2c, Figure 3a). The electron energy loss spectroscopy (EELS) mapping of the selected area of NSCF verifies the uniform distribution of $\mathrm{N}$ and $\mathrm{S}$ within the whole nanofibrous network. Besides, the selected area electron diffraction (SAED) analysis indicates the amorphous structure of NSCF (Figure 3b-g).

The pore structure of $\mathrm{CBC}$ and NSCF were investigated by $\mathrm{N}_{2}$ adsorption/desorption measurement (Figure S3). The Brunauer-Emmett-Teller (BET) surface area of pristine $\mathrm{BC}$ is as high as $705.3 \mathrm{~m}^{2} \mathrm{~g}^{-1}$, whereas, the specific surface area of NSCF is $401.4 \mathrm{~m}^{2} \mathrm{~g}^{-1}$. Such changes can be attributed to the variation in the microstructure after thiourea treatment. The pore distribution analysis also confirms the pore structure variation by showing a significantly enhanced micropore and mesopore desorption of NSCF. This is mainly owing to the pore-formation process of $\mathrm{H}_{2} \mathrm{~S}$ and $\mathrm{NH}_{3}$ during the decomposition of thiourea.

The surface elemental information of NSCF was then revealed by the X-ray photoelectron spectroscopy (XPS). XPS full survey of the CBC gives the existence of 90.24 at\% C and 9.76 at\% O (Figure S4a). For comparison, apart from C and O, the atomic percentage of $\mathrm{N}$ and $\mathrm{S}$ was calculated to be 6.90 at\% and 1.02 at\% respectively in NSCF (Figure S4b). Deconvolution of the asymmetric C1s of the NSCF (Figure 4a) gives five peaks, where the binding energies of $\mathrm{C}-\mathrm{N}(285.3 \mathrm{eV})$ and $\mathrm{C}-\mathrm{S}(283.9 \mathrm{eV})$ are clearly identified. This result implies that $\mathrm{N}$ and $\mathrm{S}$ elements have been successfully doped into the carbon framework. The high resolution N1s spectrum 
(Figure 4c) indicated that there are two species of N, namely pyridinic N (398.0 eV) and pyrrolic $\mathrm{N}$ (400.3 eV), as typically observed in the N-doped carbon materials [25]. Remarkably, regardless of the fitting procedure, no graphitic $\mathrm{N}$ is observed even it has been wildly accepted that the "three-peak fit" is better owing to the higher electrical conductivity (electrical conductivities of $\mathrm{CBC}$ and $\mathrm{NSCF}$ are $33.0 \mathrm{~S} \mathrm{~m}^{-1}$ and $64.1 \mathrm{~S}$ $\mathrm{m}^{-1}$, respectively) [26]. The high-resolution XPS spectrum of S mainly displays two

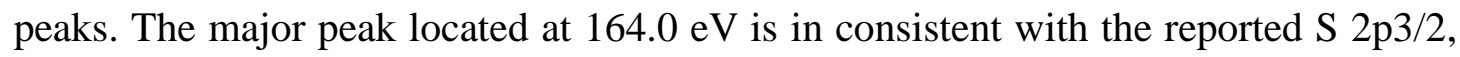
which can be attributed to the binding sulfur in $-\mathrm{C}-\mathrm{S}$ bonds. The minor peak at 168.6 $\mathrm{eV}$ belongs to the oxidized $\mathrm{S}\left(-\mathrm{SO}_{\mathrm{x}}{ }^{-}\right)$, which normally appeared at the edge of carbon skeletons [27]. These results further confirm the successful doping of $\mathrm{N}$ and $\mathrm{S}$ by using thiourea as the dopant. The high doping content of both $\mathrm{N}$ and $\mathrm{S}$ elements also suggests that the strategy is efficient and cost-saving.

The quality of the resultant CBC and NSCF was further revealed by Raman spectroscopy (Figure S5). In accordance with the typical Raman spectra of the $\mathrm{sp}^{2}$-carbons [28, 29, 30], two conspicuous peaks of CBC are observed at $1337.4 \mathrm{~cm}^{-1}$ (D band) and $1584.7 \mathrm{~cm}^{-1}$ ( $\mathrm{G}$ band). The relative intensity ratio of $\mathrm{D}$ band to $\mathrm{G}$ band $\left(\mathrm{I}_{\mathrm{D}} / \mathrm{I}_{\mathrm{G}}\right)$ is 0.995 . Compared to that of $\mathrm{CBC}$, the $\mathrm{D}$ band of NSCF shifts positively to $1345.5 \mathrm{~cm}^{-1}$, while the $\mathrm{G}$ band shifts negatively to $1585.5 \mathrm{~cm}^{-1}$, indicating an apparent modification of the fine structure by N/S co-doping. The red-shift of G-band could be attributed to the electronic structure change in carbon substrate [31]. Moreover, the $\mathrm{I}_{\mathrm{D}} / \mathrm{I}_{\mathrm{G}}$ value of NSCF (1.082) is higher than that of $\mathrm{CBC}$, indicating more defects in the carbon backbone after doping. The incorporated $\mathrm{N}$ and $\mathrm{S}$ atoms can provide free electrons and act as electron donors, which facilitates the electron transfer between valance and conduction bands [32].

Above results have verified the well-developed 3D nanofibrous structure and abundant N/S doping in NSCF, which are regarded as the promoter for ion transfer and thus enhance both the electrical double-layer capacitance and pseudo-capacitance. Then, water infiltration tests (aqueous system) were carried out to investigate the electrolyte wettability of CBC and NSCF. The original BC pellicle is surface superhydrophilic and exhibits ultra-high water holding capability. The CBC shows a 
distinct-different surface polarity (Figure 5). The water droplet remains on the surface and exhibits a very large contact angle on the CBC. Differentially, By contrast, the water droplet on the NSCF spreads out immediately and fully infiltrate into the film, demonstrating its superhydrophilicity feature. The obvious difference in wettablility can be explained by the numerous hydrophilous $\mathrm{N}$ and $\mathrm{S}$ related functionalities in NSCF, which is in consistent with the previous XPS data.

CBC and NSCF were then evaluated as electrodes for supercapacitors in a three-electrode system, and cyclic voltammetry (CV) curves of them are observed to be similar to rectangle shape (Figure 6a). Compared to the $\mathrm{CBC}$, the area under the $\mathrm{CV}$ curve of NSCF is larger, suggesting a higher specific capacitance after the N/S dual-doping. Introducing $\mathrm{N}$ and $\mathrm{S}$ atoms might provide more active sites, which will be involved in the electrochemical reactions during the charge/discharge process. $\mathrm{CV}$ curves of the NSCF at high scan rates show no obvious deformation in shape, suggesting its good capacitive behavior at high rates (Figure 6b).

According to the galvanostatic discharge/charge (GCD) curve (Figure S6), the specific capacitance of CBC is only $64 \mathrm{~F} \mathrm{~g}^{-1}$, whereas, the NSCF deliver a high value of $202 \mathrm{~F} \mathrm{~g}^{-1}$ at a current density of $1.0 \mathrm{~A} \mathrm{~g}^{-1}$ (Figure 6c). GCD curves of the NSCF at different current densities show similar triangle shape with negligible IR drop. Specific capacitances of NSCF at 0.5 and $2.0 \mathrm{~A} \mathrm{~g}^{-1}$ are 215 and $186 \mathrm{~F} \mathrm{~g}^{-1}$, respectively. Shown in Figure $6 \mathrm{~d}$ is the comparison of the IR drop values and the corresponding $\mathrm{C}_{\mathrm{s}}$ at different current densities. Even at a high current density $\left(5.0 \mathrm{~A} \mathrm{~g}^{-1}\right)$, it is observed that the IR drop is only $65 \mathrm{mV}$, and the specific capacitance is $163 \mathrm{~F} \mathrm{~g}^{-1}$, suggesting a desirable rate performance.

Subsequently, the NSCF based electrode was evaluated in a long term cyclic tests at different charge/discharge densities (Figure 7). Firstly, at the relatively low current density of $0.5 \mathrm{~A} \mathrm{~g} \mathrm{~g}^{-1}$, the specific capacitance of NSCF decrease from $214 \mathrm{~F} \mathrm{~g}^{-1}$ to $211 \mathrm{~F} \mathrm{~g}^{-1}$ in the initial 500 cycles. The attenuation at this stage could be ascribed to the permeation of electrolyte ion into the interior structure of NSCF. In this process, electrochemical reactions occurred at both the surface and the bulk phase, along with the possible of decomposition of some unstable functional groups. After a stable loop 
of another 500 cycles at $1.0 \mathrm{~A} \mathrm{~g}^{-1}$, the NSCF based electrode was cycled at $2.0 \mathrm{~A} \mathrm{~g}^{-1}$. It shows a little upward tendency at the first 300 cycles and then remained stable, which could be explained by the electrochemical activation. Finally, the electrode was subjected to a higher current density of $3.0 \mathrm{~A} \mathrm{~g}^{-1}$, giving good cycle stability during the long term cycle even up to 5000 cycles. The neglectable variation of $\mathrm{CV}$ curves of the NSCF during the whole cycling test suggests minimal structural changes during the electrochemical process (TEM image of NSCF after cycling is shown in Figure S7), which is also evidently verified the fulfilling long cycle stability of the NSCF. Electrochemical impedance spectroscopy (EIS) test was used to investigate the electrochemical properties of NSCF after cycling (Figure S9). After a long-term cycle, both of the $\mathrm{R}_{s}$ and $\mathrm{R}_{c t}$ are remained unchanged. The slope of the curve in the low frequency region is nearly vertical. The plot of Frequency vs Phase angle were compared to investigate the rate capability of NSCF. These results manifest that after the long-term cycle, the small changes occurred on NSCF might facilitate the sufficient permeation of the electrolyte, which is supposed to provide more relay stations for the electrolyte ion storage [33].

To further investigate the capacitance behaviors of NSCF, they were then analyzed in the two-electrode system. CV curves of the NSCF based device show typical rectangular shape in the range of $0-1.0 \mathrm{~V}$ in $6.0 \mathrm{M} \mathrm{KOH}$ (Figure $8 \mathrm{a}$ ). The rectangle feature is distinct even at a high scan rate of $100 \mathrm{mV} \mathrm{s}^{-1}$, indicating its desirable rate performance. According to corresponding CGD curves (Figure 8b), the calculated specific capacitances of the NSCF based device is $80 \mathrm{Fg}^{-1}$ at $0.5 \mathrm{Ag}^{-1}$. The capacitance still reaches $72 \mathrm{~F} \mathrm{~g}^{-1}$ upon a current density of $5.0 \mathrm{~A} \mathrm{~g}^{-1}$, which is $90 \%$ of the value at $0.5 \mathrm{~A} \mathrm{~g}^{-1}$ (The Ragone plots of NSCF is shown in Figure S9). The ideal linear dependence of the NSCF could be observed between the current density with scan rates ranging from 10 to $50 \mathrm{mV} \mathrm{s}^{-1}$ (Figure S10), which further supports the fast surface adsorption/desorption process of the charge storage behavior of NSCF. Judging from CV curves, the calculated specific capacitances are almost identical, which exhibited no direct connection to the scan rate (Figure S10b,c). The desirable dynamic mechanism could be explained by the robust 3D conductive framework as 
well as the favorable wettability in the aqueous electrolyte, which grantees the fast ion transportation even at a high rate. The electrochemical behaviors of NSCF was also evaluated by typical $\mathrm{CV}$ curves recorded at a scan rate of $10 \mathrm{mV} \mathrm{s}^{-1}$ in different voltage windows (i.e., 0-1.0, 0-1.1, 0-1.2, and 0-1.3 V, respectively). As shown in Figure S11a, no obvious deformation of the CV curve was detected when the potential window increases to $1.2 \mathrm{~V}$, implying irreversible reactions occurs on the electrode surface. By gradually widening the potential to $1.3 \mathrm{~V}$, the polarization phenomenon occurred at high voltage could be observed, which is mainly due to the oxygen evolution reaction. Calculated from the corresponding GCD curves, the specific capacitances remain almost the same when expanding the voltage window (Figure 11b). The above results suggest that the potential window of NSCF electrode can be extended after being doped with $\mathrm{N}$ and $\mathrm{S}$.

EIS test was then employed to further understand the effect of introducing heteroatoms on the performance. As could be seen in Figure 9a, the NSCF based device shows very low $\mathrm{R}_{s}(0.77 \Omega)$ and $\mathrm{R}_{c t}(0.34 \Omega)$ in the high frequency zone, indicating its inherent good infiltration of the electrolyte as well as the high electrical conductivity [34]. The subvertical curve appeared in the low frequency zone is regarded as the reflex of good capacitive in the fast ion diffusion process. In the Bode plot (Figure $9 \mathrm{~b}$ ), the near $90^{\circ}$ phase angle close on the $\mathrm{Y}$ axis at low frequency, and only $2.1 \mathrm{~s}$ relaxation time of the constant $\tau_{0}$ further confirms the ideal fast charge/discharge capability of the NSCF [35]. For a practical application, the NSCF based coin-cell was then conducted in long-term cycling test with a current density of $3.0 \mathrm{~A} \mathrm{~g}^{-1}$ (Figure S12). It was observed that the total attenuation in specific capacitance was only $2 \%$ based on the maximum value after the long cycle of 5000 , manifesting its great potential in a realistic device.

\section{Conclusion}

In brief, NSCF with robust 3D architecture and high N/S doping content was successfully prepared through an adsorption-swelling strategy by using BC as the carbonaceous material. The obtained NSCF showed many advantages, such as high N/S doping content, interconnecting ion transport channel, highly wettability towards 
aqueous electrolyte. When being used as electrode for supercapacitors, NSCF showed desirable electrochemical performance in both three-electrode and two-electrode tests. This work indicates that the dual-doping with well-defined structures is a promising strategy to improve the capacitive performance of carbon based materials. We believe that the as-synthesized NSCF in this work may also be applicable for catalysis, metal-ion batteries and other energy storage and conversion fields. Moreover, it also provides an alternative facile method for the full utilization of biomass material with specific morphology and architecture.

\section{Acknowledgments:}

This work was financially supported by the Program for Innovative Teams of Outstanding Young and Middle-Aged Researchers in the Higher Education Institutions of Hubei Province (T201602), the Key Program of Natural Science Foundation of Hubei Province, China (2017CFA004), and the Hubei Superior and Distinctive Discipline Group of "Mechatronics and Automobiles" (XKQ2019048, Hubei Province, China). Supports from the UOW VC Fellowship and University start-up fund (WUST) are gratefully acknowledged. The authors would like to thank the Australian National Fabrication Facility-Materials node for facility access.

\section{References}

[1] B.Z. Fang, J.H. Kim, M.I. Kim, J.S. Yu, Hierarchical nanostructured carbons with meso macroporosity: design, characterization, and applications, Accounts Chem. Res., 46 (2013) 1397-1406.

[2] L. Lin, W. Lei, S. Zhang, Y. Liu, G.G. Wallace, J. Chen, Two-dimensional transition metal dichalcogenides in supercapacitors and secondary batteries, Energy Storage Mater., 19 (2019) 408-423 .

[3] J. Zhao, H. Lai, Z. Lyu, Y. Jiang, K. Xie, X. Wang, Q. Wu, L. Yang, Z. Jin, Y. Ma, J. Liu, Z. Hu, Hydrophilic hierarchical nitrogen-doped carbon nanocages for ultrahigh supercapacitive performance, Adv. Mater., 27 (2015) 3541-3545.

[4] K. Gong, F. Du, Z. Xia, M. Durstock, L. Dai, Nitrogen-doped carbon nanotube arrays with high electrocatalytic activity for oxygen reduction, Science, 323 (2009) 760-764. 
[5] M. Hahn, M. Baertschi, O. Barbieri, J.-C. Sauter, R. Kötz, R. Gallay, Interfacial capacitance and electronic conductance of activated carbon double-layer electrodes, Electrochem. Solid ST, 7 (2004) A33-A36.

[6] T. Lin, I.-W. Chen, F. Liu, C. Yang, H. Bi, F. Xu, F. Huang, Nitrogen-doped mesoporous carbon of extraordinary capacitance for electrochemical energy storage, Science, 350 (2015) 1508-1513.

[7] Y. Deng, Y. Xie, K. Zou, X. Ji, Review on recent advances in nitrogen-doped carbons: preparations and applications in supercapacitors, J. Mater. Chem. A, 4 (2016) 1144-1173.

[8] F. Chen, J. Yang, T. Bai, B. Long, X. Zhou, Biomass waste-derived honeycomb-like nitrogen and oxygen dual-doped porous carbon for high performance lithium-sulfur batteries, Electrochimi. Acta, 192 (2016) 99-109.

[9] J. Zhu, C. Chen, Y. Lu, Y. Ge, H. Jiang, K. Fu, X. Zhang, Nitrogen-doped carbon nanofibers derived from polyacrylonitrile for use as anode material in sodium-ion batteries, Carbon, 94 (2015) 189-195.

[10] D. Zhang, Y. Zhang, Y. Luo, Y. Zhang, X. Li, X. Yu, H. Ding, P.K. Chu, L. Sun, High-performance asymmetrical supercapacitor composed of rGO-enveloped nickel phosphite hollow spheres and N/S co-doped rGO aerogel, Nano Research, 11 (2018) $1651-1663$.

[11] Z.S. Wu, A. Winter, L. Chen, Y. Sun, A. Turchanin, X. Feng, K. Mullen, Three-dimensional nitrogen and boron co-doped graphene for high-performance all-solid-state supercapacitors, Adv. Mater., 24 (2012) 5130-5135.

[12] C. Wang, Y. Zhou, L. Sun, Q. Zhao, X. Zhang, P. Wan, J. Qiu, N/P-codoped thermally reduced graphene for high-performance supercapacitor applications, J. Phys. Chem. C, 117 (2013) 14912-14919.

[13] L. Zhang, Z. Xia, Mechanisms of oxygen reduction reaction on nitrogen-doped graphene for fuel cells, J. Phys. Chem. C, 115 (2011) 11170-11176.

[14] W. Lei, W. Xiao, J. Li, G. Li, Z. Wu, C. Xuan, D. Luo, Y.P. Deng, D. Wang, Z. Chen, Highly nitrogen-doped three-dimensional carbon fibers network with superior sodium storage capacity, ACS Appl. Mater. Interfaces, 9 (2017) 28604-28611. 
[15] G. Li, W. Lei, D. Luo, Y.-P. Deng, D. Wang, Z. Chen, 3D porous carbon sheets with multidirectional ion pathways for fast and durable lithium-sulfur batteries, Adv. Energy Mater., 8 (2018) 1702381.

[16] M. Iguchi, S. Yamanaka, A. Budhiono, Bacterial cellulose-a masterpiece of nature's arts, J. Mater. Sci., 35 (2000) 261-270.

[17] M. Chen, H. Kang, Y. Gong, J. Guo, H. Zhang, R. Liu, Bacterial cellulose supported gold nanoparticles with excellent catalytic properties, ACS Appl. Mater. Interfaces, 7 (2015) 21717-21726.

[18] S. Chen, Y. Zou, Z. Yan, W. Shen, S. Shi, X. Zhang, H. Wang, Carboxymethylated-bacterial cellulose for copper and lead ion removal, J. Hazard Mater, 161 (2009) 1355-1359.

[19] Y. Huang, C. Zhu, J. Yang, Y. Nie, C. Chen, D. Sun, Recent advances in bacterial cellulose, Cellulose, 21 (2013) 1-30.

[20] W. Lei, L. Han, C. Xuan, R. Lin, H. Liu, H.L. Xin, D. Wang, Nitrogen-doped carbon nanofibers derived from polypyrrole coated bacterial cellulose as high-performance electrode materials for supercapacitors and Li-ion batteries, Electrochim. Acta, 210 (2016) 130-137.

[21] S. Kirdponpattara, M. Phisalaphong, S. Kongruang, Gelatin-bacterial cellulose composite sponges thermally cross-linked with glucose for tissue engineering applications, Carbohyd. Polym., 177 (2017) 361-368.

[22] X. Wang, J. Wang, D. Wang, S. Dou, Z. Ma, J. Wu, L. Tao, A. Shen, C. Ouyang, Q. Liu, S. Wang, One-pot synthesis of nitrogen and sulfur co-doped graphene as efficient metal-free electrocatalysts for the oxygen reduction reaction, Chem. Commun., 50 (2014) 4839-4842.

[23] S. Wang, Q. Gao, J. Wang, Thermodynamic analysis of decomposition of thiourea and thiourea oxides, J. Phys. Chem. B, 109 (2005) 17281-17289.

[24] W. Ai, Z. Luo, J. Jiang, J. Zhu, Z. Du, Z. Fan, L. Xie, H. Zhang, W. Huang, T. Yu, Nitrogen and sulfur codoped graphene: multifunctional electrode materials for high-performance li-ion batteries and oxygen reduction reaction, Adv. Mater., 26 (2014) 6186-6192. 
[25] G. Liu, X. Li, J.-W. Lee, B.N. Popov, A review of the development of nitrogen-modified carbon-based catalysts for oxygen reduction at USC, Catal. Sci. Technol., 1 (2011) 207-217.

[26] D.H. Guo, R. Shibuya, C. Akiba, S. Saji, T. Kondo, J. Nakamura, Active sites of nitrogen-doped carbon materials for oxygen reduction reaction clarified using model catalysts, Science, 351 (2016) 361-365.

[27] Y. Yan, Y.-X. Yin, S. Xin, Y.-G. Guo, L.-J. Wan, Ionothermal synthesis of sulfur-doped porous carbons hybridized with graphene as superior anode materials for lithium-ion batteries, Chem. Commun., 48 (2012) 10663-10665.

[28] L. Lin, S. Zhang, Creating high yield water soluble luminescent graphene quantum dots via exfoliating and disintegrating carbon nanotubes and graphite flakes. Chem. Commun. 48 (2012) 10177-10179.

[29] L. Lin, S. Zhang, Effective solvothermal deoxidization of graphene oxide using solid sulphur as a reducing agent. J. Mater. Chem. 22 (2012) 14385-14393.

[30] W. Lei, H. Liu, J. Xiao, Y. Wang, L. Lin, Moss-derived mesoporous carbon as bi-functional electrode materials for lithium-sulfur batteries and supercapacitors. Nanomaterials 9 (2019) 84.

[31] Q.-H. Yang, P.-X. Hou, M. Unno, S. Yamauchi, R. Saito, T. Kyotani, Dual Raman features of double coaxial carbon nanotubes with $\mathrm{N}$-doped and B-doped multiwalls, Nano Lett., 5 (2005) 2465-2469.

[32] J.P. Paraknowitsch, A. Thomas, Doping carbons beyond nitrogen: an overview of advanced heteroatom doped carbons with boron, sulphur and phosphorus for energy applications, Energ. Environ. Sci., 6 (2013) 2839.

[33] Y. Wang, C.X. Guo, J. Liu, T. Chen, H. Yang, C.M. Li, $\mathrm{CeO}_{2}$ nanoparticles/graphene nanocomposite-based high performance supercapacitor, Dalton Trans, 40 (2011) 6388-6391.

[34] S.H. Aboutalebi, A.T. Chidembo, M. Salari, K. Konstantinov, D. Wexler, H.K. Liu, S.X. Dou, Comparison of GO, GO/MWCNTs composite and MWCNTs as potential electrode materials for supercapacitors, Energ. Environ. Sci., 4 (2011).

[35] B.E. Conway, V. Birss, J. Wojtowicz, The role and utilization of 
pseudocapacitance for energy storage by supercapacitors, J. Power Sources, 66 (1997) $1-14$. 


\section{Fabrication of Nitrogen and Sulfur Co-Doped Carbon Nanofibers with Three-Dimensional Architecture for High \\ Performance Supercapacitors}

Wen Lei ${ }^{a}$, Haijun Zhang ${ }^{a}$, Dezheng Liu, ${ }^{b *}$ and Liangxu Lin ${ }^{a, c^{*}}$

${ }^{a}$ The State Key Laboratory of Refractories and Metallurgy, and Institute of Advanced Materials and Nanotechnology, Wuhan University of Science and Technology, Wuhan, 430081, China

${ }^{\mathrm{b}}$ Department of Mechanical Engineering, Hubei University of Arts and Science, Xiangyang, Hubei 441053, China

${ }^{\mathrm{c}}$ ARC Centre of Excellence for Electromaterials Science, Intelligent Polymer Research Institute, Australia Institute of Innovative Materials (AIIM), Innovation Campus, University of Wollongong, Wollongong 2500, Australia

Abstract: Making full use of the high water-holding capability of bacterial cellulose, a highly N/S dual-doped carbon fibers (NSCF) with interconnected three dimensional structure is prepared by an absorption-swelling strategy. Supercapacitor electrode fabricated from this material delivers a high specific capacitance of $202 \mathrm{~F} \mathrm{~g}^{-1}$, which is two times higher than that of the pristine un-doped one at current density of $1.0 \mathrm{~A}$ $\mathrm{g}^{-1}$. This dual-doped NSCF shows good wettability, fast ion-transportation and desirable electrical conductivity, which are indispensable characters of an electrode material in building the supercapacitor with desired high power performances.

Keywords: Bacterial cellulose; three dimensional; N/S co-doping; supercapacitors

\section{Introduction}

Owing to their multitudinous structural, morphological and chemical properties, carbon materials have found good applications in different fields, particularly as electrode material of supercapacitors [1]. Such carbon materials should be appropriately modified to satisfy the increasing demand on the high energy and power performances of nowadays energy storage devices [2].

So far, numerous reports have verified the positive effects of heteroatoms

${ }^{*}$ Corresponding author. E-mail: liudezheng@hbuas.edu.cn. Tel.: (+86) 0710-3592271.

*Corresponding author. E-mail: L.Lin@wust.edu.cn. Tel.: (+86) 027-68862825. 
doping on the electrochemical property enhancement of carbon materials, and put forward the following mechanisms: 1) the improvement of electrode wettability owing to the increased hydrophilic polar sites [3];2) the enhancement in electrical conductivity owing to the newly introduced charge carrier at the conduction band [4]; 3) the occurrence of space-charge-layer capacitance by increasing its electron density [5] and 4) the appearance of pseudo-capacitance derived from the surface faradaic reaction because of the electronegativity difference between the carbon and the incorporated heteroatoms [6]. Till now, several methods, including the in-situ doping strategy and post-processing treatment, have been attempted to introduce heteroatoms into the carbon framework [7]. The in-situ doping strategy normally involves a direct carbonization process of heteroatoms containing carbonaceous materials (e.g. biomass materials [8] and organic compounds [9]). As for the post-processing treatment, carbon materials are normally mixed and reacted with the functional dopant (e.g. ammonia gas, urea and boric acid) under appropriate heat treatment [7]. Even so, the improvement in the capacitance behaviors was still limited due to the low content of the dopant. In this regard, the dual-heteroatoms doping strategy was proposed to further improve the capacitance. Besides the benefit from the synergistic effects between different dopants, such a strategy can also improve the ratio of dopants.

For instance, N/S co-doped graphene [10], B/N co-doped carbon material [11] and N/P co-doped graphene [12] have been prepared with energy storage capacitance superior to their undoped and single element doping counterparts. Among diversified doping forms mentioned above, N/S co-doping has been considered more promising owing to the significant changes in spin density, the polarisability as well as the structural defects caused by the bigger diameter of sulfur's atom [13]. However, the state of the art strategies for preparing N/S co-doped carbon materials are always complicated, as it also largely involves different features (e.g. size, morphology, porous structure) of various raw materials. Different approaches have been made in this regard $[14,15]$, but how to concisely fabricate the heteroatom-doped carbon material with rational designed structure and 
high heteroatoms doping content at a low-cost level is still a challenge.

In this work, we put forward a concise and efficient alternative choice to produce nitrogen and sulfur co-doped carbon nanofibers (NSCF) from the bacterial cellulose (BC). As the masterpiece of nature's art, BC has many interesting features such as the ultrafine three-dimensional (3D) network, excellent biodegradability and biocompatibility [16] [17] [18], giving significant inherent advantages in severing as the precursor for porous carbon structure [19]. The loose arrangement of nanofibers, the high specific surface area and the hydrophilic nature of $\mathrm{BC}$ endow an ultra-high water holding capacity (> 200 times of its dry weight), making it an ideal platform of holding dopants with high ratio [20] [21]. Starting from the simple strategy of adsorption and swelling, the thin BC pellicle (never-dried) was used to absorb the saturated thiourea solution and then transformed to the NSCF which possess many favorable properties (e.g. high wettability, high electrical conductivity and robust 3D architecture) for supercapacitors. By way of example, we demonstrate a capacitance of $202 \mathrm{~F} \mathrm{~g}^{-1}$ at the current density of $1.0 \mathrm{~A} \mathrm{~g}^{-1}$, and a long-term cycling performance up to 5000 cycles without obvious capacitance fading.

\section{Experimental section}

2.1 Pretreatment of BC: BC membrane, kindly provided by Prof. Chonghua Pei (School of Materials Science and Engineering, Southwest University of Science and Technology), was immersed into a solution of $0.10 \mathrm{M} \mathrm{NaOH}$ at $50{ }^{\circ} \mathrm{C}$ for $2 \mathrm{~h}$ to remove bacteria and residues, and then thoroughly washed with distilled water until $\mathrm{pH}$ is close to 7 .

2.2 Preparation of NSCF: The gel-like pre-treated BC pellicle was pressed under a $10 \mathrm{~kg}$ stainless steel plate for $10 \mathrm{~h}$ to remove the holding water and then cut into rectangular pieces sized $2 \times 2 \mathrm{~cm}$ (make sure the membrane still contains moisture). Afterwards, the obtained thin $\mathrm{BC}$ piece (defined as never-dried $\mathrm{BC}$ membrane) was immersed into a saturated thiourea aqueous solution for $48 \mathrm{~h}$ until it fully swelled to its normal shape. The swelled piece was then frozen in liquid nitrogen and immediately placed in a freezer drier (sublimating temperature of $-55^{\circ} \mathrm{C}$, pressure of $0.015 \mathrm{mbar}$ ) for $48 \mathrm{~h}$ to remove water. The as-obtained $\mathrm{BC}$ thiourea lump was then 
directly calcined under Ar atmosphere protection with a set temperature programming $\left(2.0^{\circ} \mathrm{C} \mathrm{min}{ }^{-1}\right.$ to $500{ }^{\circ} \mathrm{C}$ for $1.0 \mathrm{~h}$ and then at $5.0^{\circ} \mathrm{C} \mathrm{min}{ }^{-1}$ to $850{ }^{\circ} \mathrm{C}$ for $2.0 \mathrm{~h}$ ). Finally, the black product was obtained. As a control, the undoped carbonized BC, namely $\mathrm{CBC}$, was prepared by direct carbonization of the freeze-dried $\mathrm{BC}$ membrane at the identical temperature programming.

\subsection{Material characterization}

Scanning transmission electron microscopy (S-TEM) and TEM images were obtained on STEM (Tecnai G2 F30). Elemental mapping were conducted using EDAX detector attached on Tecnai G2 F30. Thermal gravimetric analysis (TGA) was conducted on Pyris1 TGA Instrument at $30-800{ }^{\circ} \mathrm{C}$ in a $10 \mathrm{~mL} \mathrm{~min}^{-1} \mathrm{~N}_{2}$ flow with a heating rate of $10{ }^{\circ} \mathrm{C} \min ^{-1}$. X-ray photoelectron spectroscopic (XPS) were collected on an AXIS-ULTRA DLD-600W Instrument. FTIR measurements were conducted on a Bruker Vector-22 FTIR spectrometer at $4000-500 \mathrm{~cm}^{-1}$. Raman spectra were taken by a LabRam HR800 spectrometer with a $532 \mathrm{~nm}$ laser excitation. The electronic conductivities were studied by the four-probe method with a ST-2258C multifunction digital four-probe tester.

$\mathrm{N}_{2}$ sorption analysis was carried out on an ASAP 2020 accelerated surface area and porosimetry instrument (Micromeritics), equipped with an automated surface area, at $77 \mathrm{~K}$ using Barrett-Emmett-Teller (BET) calculations for the surface area. The pore size distribution (PSD) plot was produced with the adsorption branch of the isotherm based on the Barrett-Joyner-Halenda (BJH) model. The CHN analysis was carried out using an Elementarvario EL cube.

\subsection{Electrochemical tests}

6.0 $\mathrm{M} \mathrm{KOH}$ solution was used as electrolyte in all experiments at room temperature. The working electrode was prepared by taking active material, conductive additive (acetylene black), and binder (PTFE) in the weight ratio (80:10:10) and mixed together with ethanol to obtain the slurry. The mass load of each electrode is about 3.0 $\mathrm{mg} \mathrm{cm}^{-2}$. For three-electrode test: All electrochemical measurements were carried out by using platinum sheet as counter electrode, as-prepared electrode as working electrode referred to $\mathrm{Ag} / \mathrm{AgCl}$ reference electrode. For two-electrode test, the 
as-prepared electrodes were assembled to the symmetric cell in a 2032-type coin cell. Cyclic voltammetry (CV), electrochemical impedance spectroscopy (EIS) and galvanostatic charge/discharge (GCD) tests were all performed with $\mathrm{CHI}$ 760e electrochemical workstation (CH Instruments, China). $\mathrm{CV}$ and $\mathrm{GCD}$ tests were performed between -1.0 and $0 \mathrm{~V}$. The specific capacitance was calculated based on the equation $\mathrm{C}_{\mathrm{s}}=\mathrm{It} / \mathrm{m} \Delta \mathrm{V}$. EIS tests were performed at open-circuit potential in the frequency range from $100 \mathrm{kHz}$ to $0.01 \mathrm{~Hz}$ with an AC perturbation of $5 \mathrm{mV}$.

\section{Results}

As illustrated in Figure 1, the NSCF was prepared through a facial two-step doping procedure. The pre-treated never-dried thin BC pellicle with a thickness of 0.1 $\mathrm{cm}$, was immersed in the saturated thiourea aqueous solution until it reached the swelling equilibrium state after $48 \mathrm{~h}$ (Figure 1a). The obtained swelled BC pellicle was treated with liquid nitrogen and then freeze-dried to remove water (Digital photograph of dried BC lump is shown in Figure S1). Since BC has already a high initial level of inter-fiber bonding through extensive hydrogen bonding of continuous nano-ribbons, $\mathrm{N}-\mathrm{H}$ groups of thiourea were supposed to form multitopic hydrogen bonds with the hydroxyl group of BC (Figure 1b). Therefore, during the high temperature treatment, $\mathrm{N}$ and $\mathrm{S}$ contained functionalities from thiourea could be covalently attached onto the $\mathrm{BC}$ or $\mathrm{BC}$ derived carbon, and were then incorporated into the carbon framework [22].

According to the thermogravimetric analyzer (TGA) result (in $\mathrm{N}_{2}$ atmosphere), the thermosol temperature of thiourea is around $200{ }^{\circ} \mathrm{C}$ (Figure 2a). During this period, the isomerization of thiourea could be observed. Along with the temperature increases, some gases (e.g. $\mathrm{NH}_{3}, \mathrm{H}_{2} \mathrm{~S}, \mathrm{SO}_{\mathrm{x}}$ ) would be released and attached on the surface of $\mathrm{BC}$ [23]. After the calcination, the X-ray diffraction (XRD) pattern of the $\mathrm{CBC}$ shows a diffraction peak at $25.8^{\circ}$, while NSCF exhibits a broader peak at $23.7^{\circ}$, suggesting a much larger interlayer spacing induced by the N/S co-doping (Figure 2b). The broadened full width at half maximum and the significantly decreased intensity of the NSCF imply a much lower graphitization degree owing to the N/S co-doping [24].

Scanning electron microscope (SEM) and transmission electron microscope 
(TEM) characterizations were then performed to investigate the morphology of samples. As shown as the SEM image (Figure S2a), the pristine BC presents an interconnected 3D nanofibrous structure with the fiber diameter of about $30 \mathrm{~nm}$ and a length ranging from micrometers to dozens of micrometers. This unique 3D interwoven structure contains numerous - $\mathrm{OH}$ groups, which can act as bridging ligands for assembling nanoscaled building units to control the desired morphology. Moreover, the 3D network-like structure is favorable for increasing the effective reaction surface and facilitates its combination to thiourea. The obtained $\mathrm{CBC}$ inherited the morphology of $\mathrm{BC}$ after the calcination at $850^{\circ} \mathrm{C}$ (Figure S2b). Similarly, NSCF shows exactly the same nanofibrous morphology as that of CBC (Figure S2c, Figure 3a). The electron energy loss spectroscopy (EELS) mapping of the selected area of NSCF verifies the uniform distribution of $\mathrm{N}$ and $\mathrm{S}$ within the whole nanofibrous network. Besides, the selected area electron diffraction (SAED) analysis indicates the amorphous structure of NSCF (Figure 3b-g).

The pore structure of $\mathrm{CBC}$ and NSCF were investigated by $\mathrm{N}_{2}$ adsorption/desorption measurement (Figure S3). The Brunauer-Emmett-Teller (BET) surface area of pristine BC is as high as $705.3 \mathrm{~m}^{2} \mathrm{~g}^{-1}$, whereas, the specific surface area of NSCF is $401.4 \mathrm{~m}^{2} \mathrm{~g}^{-1}$. Such changes can be attributed to the variation in the microstructure after thiourea treatment. The pore distribution analysis also confirms the pore structure variation by showing a significantly enhanced micropore and mesopore desorption of NSCF. This is mainly owing to the pore-formation process of $\mathrm{H}_{2} \mathrm{~S}$ and $\mathrm{NH}_{3}$ during the decomposition of thiourea.

The surface elemental information of NSCF was then revealed by the X-ray photoelectron spectroscopy (XPS). XPS full survey of the CBC gives the existence of 90.24 at\% C and 9.76 at\% O (Figure S4a). For comparison, apart from C and O, the atomic percentage of $\mathrm{N}$ and $\mathrm{S}$ was calculated to be 6.90 at $\%$ and 1.02 at $\%$ respectively in NSCF (Figure S4b). Deconvolution of the asymmetric C1s of the NSCF (Figure 4a) gives five peaks, where the binding energies of $\mathrm{C}-\mathrm{N}(285.3 \mathrm{eV})$ and $\mathrm{C}-\mathrm{S}(283.9 \mathrm{eV})$ are clearly identified. This result implies that $\mathrm{N}$ and $\mathrm{S}$ elements have been successfully doped into the carbon framework. The high resolution N1s spectrum 
(Figure 4c) indicated that there are two species of $\mathrm{N}$, namely pyridinic $\mathrm{N}(398.0 \mathrm{eV})$ and pyrrolic $\mathrm{N}(400.3 \mathrm{eV})$, as typically observed in the N-doped carbon materials [25]. Remarkably, regardless of the fitting procedure, no graphitic $\mathrm{N}$ is observed even it has been wildly accepted that the "three-peak fit" is better owing to the higher electrical conductivity (electrical conductivities of CBC and NSCF are $33.0 \mathrm{~S} \mathrm{~m}^{-1}$ and $64.1 \mathrm{~S}$ $\mathrm{m}^{-1}$, respectively) [26]. The high-resolution XPS spectrum of S mainly displays two

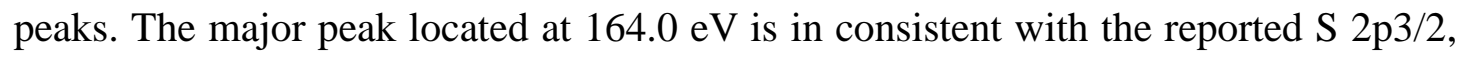
which can be attributed to the binding sulfur in $-\mathrm{C}-\mathrm{S}$ bonds. The minor peak at 168.6 $\mathrm{eV}$ belongs to the oxidized $\mathrm{S}\left(-\mathrm{SO}_{\mathrm{x}}{ }^{-}\right)$, which normally appeared at the edge of carbon skeletons [27]. These results further confirm the successful doping of $\mathrm{N}$ and $\mathrm{S}$ by using thiourea as the dopant. The high doping content of both $\mathrm{N}$ and $\mathrm{S}$ elements also suggests that the strategy is efficient and cost-saving.

The quality of the resultant $\mathrm{CBC}$ and NSCF was further revealed by Raman spectroscopy (Figure S5). In accordance with the typical Raman spectra of the $\mathrm{sp}^{2}$-carbons [28, 29,30], two conspicuous peaks of CBC are observed at $1337.4 \mathrm{~cm}^{-1}$ ( $D$ band) and $1584.7 \mathrm{~cm}^{-1}$ ( $\mathrm{G}$ band). The relative intensity ratio of $\mathrm{D}$ band to $\mathrm{G}$ band $\left(\mathrm{I}_{\mathrm{D}} / \mathrm{I}_{\mathrm{G}}\right)$ is 0.995 . Compared to that of $\mathrm{CBC}$, the $\mathrm{D}$ band of NSCF shifts positively to $1345.5 \mathrm{~cm}^{-1}$, while the $\mathrm{G}$ band shifts negatively to $1585.5 \mathrm{~cm}^{-1}$, indicating an apparent modification of the fine structure by N/S co-doping. The red-shift of G-band could be attributed to the electronic structure change in carbon substrate [31]. Moreover, the $\mathrm{I}_{\mathrm{D}} / \mathrm{I}_{\mathrm{G}}$ value of NSCF (1.082) is higher than that of $\mathrm{CBC}$, indicating more defects in the carbon backbone after doping. The incorporated $\mathrm{N}$ and $\mathrm{S}$ atoms can provide free electrons and act as electron donors, which facilitates the electron transfer between valance and conduction bands [32].

Above results have verified the well-developed 3D nanofibrous structure and abundant N/S doping in NSCF, which are regarded as the promoter for ion transfer and thus enhance both the electrical double-layer capacitance and pseudo-capacitance. Then, water infiltration tests (aqueous system) were carried out to investigate the electrolyte wettability of CBC and NSCF. The original BC pellicle is surface superhydrophilic and exhibits ultra-high water holding capability. The CBC shows a 
distinct-different surface polarity (Figure 5). The water droplet remains on the surface and exhibits a very large contact angle on the CBC. Differentially, By contrast, the water droplet on the NSCF spreads out immediately and fully infiltrate into the film, demonstrating its superhydrophilicity feature. The obvious difference in wettablility can be explained by the numerous hydrophilous $\mathrm{N}$ and $\mathrm{S}$ related functionalities in NSCF, which is in consistent with the previous XPS data.

CBC and NSCF were then evaluated as electrodes for supercapacitors in a three-electrode system, and cyclic voltammetry (CV) curves of them are observed to be similar to rectangle shape (Figure 6a). Compared to the $\mathrm{CBC}$, the area under the $\mathrm{CV}$ curve of NSCF is larger, suggesting a higher specific capacitance after the N/S dual-doping. Introducing $\mathrm{N}$ and $\mathrm{S}$ atoms might provide more active sites, which will be involved in the electrochemical reactions during the charge/discharge process. $\mathrm{CV}$ curves of the NSCF at high scan rates show no obvious deformation in shape, suggesting its good capacitive behavior at high rates (Figure 6b).

According to the galvanostatic discharge/charge (GCD) curve (Figure S6), the specific capacitance of CBC is only $64 \mathrm{~F} \mathrm{~g}^{-1}$, whereas, the NSCF deliver a high value of $202 \mathrm{~F} \mathrm{~g}^{-1}$ at a current density of $1.0 \mathrm{~A} \mathrm{~g}^{-1}$ (Figure $6 \mathrm{c}$ ). GCD curves of the NSCF at different current densities show similar triangle shape with negligible IR drop. Specific capacitances of NSCF at 0.5 and $2.0 \mathrm{Ag}^{-1}$ are 215 and $186 \mathrm{~F} \mathrm{~g}^{-1}$, respectively. Shown in Figure $6 \mathrm{~d}$ is the comparison of the IR drop values and the corresponding $\mathrm{C}_{\mathrm{s}}$ at different current densities. Even at a high current density $\left(5.0 \mathrm{~A} \mathrm{~g}^{-1}\right)$, it is observed that the IR drop is only $65 \mathrm{mV}$, and the specific capacitance is $163 \mathrm{~F} \mathrm{~g}^{-1}$, suggesting a desirable rate performance.

Subsequently, the NSCF based electrode was evaluated in a long term cyclic tests at different charge/discharge densities (Figure 7). Firstly, at the relatively low current density of $0.5 \mathrm{~A} \mathrm{~g} \mathrm{~g}^{-1}$, the specific capacitance of NSCF decrease from $214 \mathrm{~F} \mathrm{~g}^{-1}$ to $211 \mathrm{~F} \mathrm{~g}^{-1}$ in the initial 500 cycles. The attenuation at this stage could be ascribed to the permeation of electrolyte ion into the interior structure of NSCF. In this process, electrochemical reactions occurred at both the surface and the bulk phase, along with the possible of decomposition of some unstable functional groups. After a stable loop 
of another 500 cycles at $1.0 \mathrm{~A} \mathrm{~g}^{-1}$, the NSCF based electrode was cycled at $2.0 \mathrm{~A} \mathrm{~g}^{-1}$. It shows a little upward tendency at the first 300 cycles and then remained stable, which could be explained by the electrochemical activation. Finally, the electrode was subjected to a higher current density of $3.0 \mathrm{~A} \mathrm{~g}^{-1}$, giving good cycle stability during the long term cycle even up to 5000 cycles. The neglectable variation of CV curves of the NSCF during the whole cycling test suggests minimal structural changes during the electrochemical process (TEM image of NSCF after cycling is shown in Figure S7), which is also evidently verified the fulfilling long cycle stability of the NSCF. Electrochemical impedance spectroscopy (EIS) test was used to investigate the electrochemical properties of NSCF after cycling (Figure S9). After a long-term cycle, both of the $\mathrm{R}_{s}$ and $\mathrm{R}_{c t}$ are remained unchanged. The slope of the curve in the low frequency region is nearly vertical. The plot of Frequency vs Phase angle were compared to investigate the rate capability of NSCF. These results manifest that after the long-term cycle, the small changes occurred on NSCF might facilitate the sufficient permeation of the electrolyte, which is supposed to provide more relay stations for the electrolyte ion storage [33].

To further investigate the capacitance behaviors of NSCF, they were then analyzed in the two-electrode system. CV curves of the NSCF based device show typical rectangular shape in the range of $0-1.0 \mathrm{~V}$ in $6.0 \mathrm{M} \mathrm{KOH}$ (Figure $8 \mathrm{a}$ ). The rectangle feature is distinct even at a high scan rate of $100 \mathrm{mV} \mathrm{s}^{-1}$, indicating its desirable rate performance. According to corresponding CGD curves (Figure 8b), the calculated specific capacitances of the NSCF based device is $80 \mathrm{Fg}^{-1}$ at $0.5 \mathrm{Ag}^{-1}$. The capacitance still reaches $72 \mathrm{~F} \mathrm{~g}^{-1}$ upon a current density of $5.0 \mathrm{~A} \mathrm{~g}^{-1}$, which is $90 \%$ of the value at $0.5 \mathrm{~A} \mathrm{~g}^{-1}$ (The Ragone plots of NSCF is shown in Figure S9). The ideal linear dependence of the NSCF could be observed between the current density with scan rates ranging from 10 to $50 \mathrm{mV} \mathrm{s}^{-1}$ (Figure S10), which further supports the fast surface adsorption/desorption process of the charge storage behavior of NSCF. Judging from CV curves, the calculated specific capacitances are almost identical, which exhibited no direct connection to the scan rate (Figure S10b,c). The desirable dynamic mechanism could be explained by the robust 3D conductive framework as 
well as the favorable wettability in the aqueous electrolyte, which grantees the fast ion transportation even at a high rate. The electrochemical behaviors of NSCF was also evaluated by typical $\mathrm{CV}$ curves recorded at a scan rate of $10 \mathrm{mV} \mathrm{s}^{-1}$ in different voltage windows (i.e., $0-1.0,0-1.1,0-1.2$, and $0-1.3 \mathrm{~V}$, respectively). As shown in Figure S11a, no obvious deformation of the CV curve was detected when the potential window increases to $1.2 \mathrm{~V}$, implying irreversible reactions occurs on the electrode surface. By gradually widening the potential to $1.3 \mathrm{~V}$, the polarization phenomenon occurred at high voltage could be observed, which is mainly due to the oxygen evolution reaction. Calculated from the corresponding GCD curves, the specific capacitances remain almost the same when expanding the voltage window (Figure 11b). The above results suggest that the potential window of NSCF electrode can be extended after being doped with $\mathrm{N}$ and $\mathrm{S}$.

EIS test was then employed to further understand the effect of introducing heteroatoms on the performance. As could be seen in Figure 9a, the NSCF based device shows very low $\mathrm{R}_{s}(0.77 \Omega)$ and $\mathrm{R}_{c t}(0.34 \Omega)$ in the high frequency zone, indicating its inherent good infiltration of the electrolyte as well as the high electrical conductivity [34]. The subvertical curve appeared in the low frequency zone is regarded as the reflex of good capacitive in the fast ion diffusion process. In the Bode plot (Figure 9b), the near $90^{\circ}$ phase angle close on the $\mathrm{Y}$ axis at low frequency, and only $2.1 \mathrm{~s}$ relaxation time of the constant $\tau_{0}$ further confirms the ideal fast charge/discharge capability of the NSCF [35]. For a practical application, the NSCF based coin-cell was then conducted in long-term cycling test with a current density of $3.0 \mathrm{~A} \mathrm{~g}^{-1}$ (Figure S12). It was observed that the total attenuation in specific capacitance was only $2 \%$ based on the maximum value after the long cycle of 5000 , manifesting its great potential in a realistic device.

\section{Conclusion}

In brief, NSCF with robust 3D architecture and high N/S doping content was successfully prepared through an adsorption-swelling strategy by using $\mathrm{BC}$ as the carbonaceous material. The obtained NSCF showed many advantages, such as high $\mathrm{N} / \mathrm{S}$ doping content, interconnecting ion transport channel, highly wettability towards 
aqueous electrolyte. When being used as electrode for supercapacitors, NSCF showed desirable electrochemical performance in both three-electrode and two-electrode tests. This work indicates that the dual-doping with well-defined structures is a promising strategy to improve the capacitive performance of carbon based materials. We believe that the as-synthesized NSCF in this work may also be applicable for catalysis, metal-ion batteries and other energy storage and conversion fields. Moreover, it also provides an alternative facile method for the full utilization of biomass material with specific morphology and architecture.

\section{Acknowledgments:}

This work was financially supported by the Program for Innovative Teams of Outstanding Young and Middle-Aged Researchers in the Higher Education Institutions of Hubei Province (T201602), the Key Program of Natural Science Foundation of Hubei Province, China (2017CFA004), and the Hubei Superior and Distinctive Discipline Group of "Mechatronics and Automobiles" (XKQ2019048, Hubei Province, China). Supports from the UOW VC Fellowship and University start-up fund (WUST) are gratefully acknowledged. The authors would like to thank the Australian National Fabrication Facility-Materials node for facility access.

\section{References}

[1] B.Z. Fang, J.H. Kim, M.I. Kim, J.S. Yu, Hierarchical nanostructured carbons with meso macroporosity: design, characterization, and applications, Accounts Chem. Res., 46 (2013) 1397-1406.

[2] L. Lin, W. Lei, S. Zhang, Y. Liu, G.G. Wallace, J. Chen, Two-dimensional transition metal dichalcogenides in supercapacitors and secondary batteries, Energy Storage Mater., 19 (2019) 408-423 .

[3] J. Zhao, H. Lai, Z. Lyu, Y. Jiang, K. Xie, X. Wang, Q. Wu, L. Yang, Z. Jin, Y. Ma, J. Liu, Z. Hu, Hydrophilic hierarchical nitrogen-doped carbon nanocages for ultrahigh supercapacitive performance, Adv. Mater., 27 (2015) 3541-3545.

[4] K. Gong, F. Du, Z. Xia, M. Durstock, L. Dai, Nitrogen-doped carbon nanotube arrays with high electrocatalytic activity for oxygen reduction, Science, 323 (2009) 760-764. 
[5] M. Hahn, M. Baertschi, O. Barbieri, J.-C. Sauter, R. Kötz, R. Gallay, Interfacial capacitance and electronic conductance of activated carbon double-layer electrodes, Electrochem. Solid ST, 7 (2004) A33-A36.

[6] T. Lin, I.-W. Chen, F. Liu, C. Yang, H. Bi, F. Xu, F. Huang, Nitrogen-doped mesoporous carbon of extraordinary capacitance for electrochemical energy storage, Science, 350 (2015) 1508-1513.

[7] Y. Deng, Y. Xie, K. Zou, X. Ji, Review on recent advances in nitrogen-doped carbons: preparations and applications in supercapacitors, J. Mater. Chem. A, 4 (2016) $1144-1173$.

[8] F. Chen, J. Yang, T. Bai, B. Long, X. Zhou, Biomass waste-derived honeycomb-like nitrogen and oxygen dual-doped porous carbon for high performance lithium-sulfur batteries, Electrochimi. Acta, 192 (2016) 99-109.

[9] J. Zhu, C. Chen, Y. Lu, Y. Ge, H. Jiang, K. Fu, X. Zhang, Nitrogen-doped carbon nanofibers derived from polyacrylonitrile for use as anode material in sodium-ion batteries, Carbon, 94 (2015) 189-195.

[10] D. Zhang, Y. Zhang, Y. Luo, Y. Zhang, X. Li, X. Yu, H. Ding, P.K. Chu, L. Sun, High-performance asymmetrical supercapacitor composed of rGO-enveloped nickel phosphite hollow spheres and N/S co-doped rGO aerogel, Nano Research, 11 (2018) $1651-1663$.

[11] Z.S. Wu, A. Winter, L. Chen, Y. Sun, A. Turchanin, X. Feng, K. Mullen, Three-dimensional nitrogen and boron co-doped graphene for high-performance all-solid-state supercapacitors, Adv. Mater., 24 (2012) 5130-5135.

[12] C. Wang, Y. Zhou, L. Sun, Q. Zhao, X. Zhang, P. Wan, J. Qiu, N/P-codoped thermally reduced graphene for high-performance supercapacitor applications, J. Phys. Chem. C, 117 (2013) 14912-14919.

[13] L. Zhang, Z. Xia, Mechanisms of oxygen reduction reaction on nitrogen-doped graphene for fuel cells, J. Phys. Chem. C, 115 (2011) 11170-11176.

[14] W. Lei, W. Xiao, J. Li, G. Li, Z. Wu, C. Xuan, D. Luo, Y.P. Deng, D. Wang, Z. Chen, Highly nitrogen-doped three-dimensional carbon fibers network with superior sodium storage capacity, ACS Appl. Mater. Interfaces, 9 (2017) 28604-28611. 
[15] G. Li, W. Lei, D. Luo, Y.-P. Deng, D. Wang, Z. Chen, 3D porous carbon sheets with multidirectional ion pathways for fast and durable lithium-sulfur batteries, Adv. Energy Mater., 8 (2018) 1702381.

[16] M. Iguchi, S. Yamanaka, A. Budhiono, Bacterial cellulose-a masterpiece of nature's arts, J. Mater. Sci., 35 (2000) 261-270.

[17] M. Chen, H. Kang, Y. Gong, J. Guo, H. Zhang, R. Liu, Bacterial cellulose supported gold nanoparticles with excellent catalytic properties, ACS Appl. Mater. Interfaces, 7 (2015) 21717-21726.

[18] S. Chen, Y. Zou, Z. Yan, W. Shen, S. Shi, X. Zhang, H. Wang, Carboxymethylated-bacterial cellulose for copper and lead ion removal, J. Hazard Mater, 161 (2009) 1355-1359.

[19] Y. Huang, C. Zhu, J. Yang, Y. Nie, C. Chen, D. Sun, Recent advances in bacterial cellulose, Cellulose, 21 (2013) 1-30.

[20] W. Lei, L. Han, C. Xuan, R. Lin, H. Liu, H.L. Xin, D. Wang, Nitrogen-doped carbon nanofibers derived from polypyrrole coated bacterial cellulose as high-performance electrode materials for supercapacitors and Li-ion batteries, Electrochim. Acta, 210 (2016) 130-137.

[21] S. Kirdponpattara, M. Phisalaphong, S. Kongruang, Gelatin-bacterial cellulose composite sponges thermally cross-linked with glucose for tissue engineering applications, Carbohyd. Polym., 177 (2017) 361-368.

[22] X. Wang, J. Wang, D. Wang, S. Dou, Z. Ma, J. Wu, L. Tao, A. Shen, C. Ouyang, Q. Liu, S. Wang, One-pot synthesis of nitrogen and sulfur co-doped graphene as efficient metal-free electrocatalysts for the oxygen reduction reaction, Chem. Commun., 50 (2014) 4839-4842.

[23] S. Wang, Q. Gao, J. Wang, Thermodynamic analysis of decomposition of thiourea and thiourea oxides, J. Phys. Chem. B, 109 (2005) 17281-17289.

[24] W. Ai, Z. Luo, J. Jiang, J. Zhu, Z. Du, Z. Fan, L. Xie, H. Zhang, W. Huang, T. Yu, Nitrogen and sulfur codoped graphene: multifunctional electrode materials for high-performance li-ion batteries and oxygen reduction reaction, Adv. Mater., 26 (2014) 6186-6192. 
[25] G. Liu, X. Li, J.-W. Lee, B.N. Popov, A review of the development of nitrogen-modified carbon-based catalysts for oxygen reduction at USC, Catal. Sci. Technol., 1 (2011) 207-217.

[26] D.H. Guo, R. Shibuya, C. Akiba, S. Saji, T. Kondo, J. Nakamura, Active sites of nitrogen-doped carbon materials for oxygen reduction reaction clarified using model catalysts, Science, 351 (2016) 361-365.

[27] Y. Yan, Y.-X. Yin, S. Xin, Y.-G. Guo, L.-J. Wan, Ionothermal synthesis of sulfur-doped porous carbons hybridized with graphene as superior anode materials for lithium-ion batteries, Chem. Commun., 48 (2012) 10663-10665.

[28] L. Lin, S. Zhang, Creating high yield water soluble luminescent graphene quantum dots via exfoliating and disintegrating carbon nanotubes and graphite flakes. Chem. Commun. 48 (2012) 10177-10179.

[29] L. Lin, S. Zhang, Effective solvothermal deoxidization of graphene oxide using solid sulphur as a reducing agent. J. Mater. Chem. 22 (2012) 14385-14393.

[30] W. Lei, H. Liu, J. Xiao, Y. Wang, L. Lin, Moss-derived mesoporous carbon as bi-functional electrode materials for lithium-sulfur batteries and supercapacitors. Nanomaterials 9 (2019) 84.

[31] Q.-H. Yang, P.-X. Hou, M. Unno, S. Yamauchi, R. Saito, T. Kyotani, Dual Raman features of double coaxial carbon nanotubes with $\mathrm{N}$-doped and B-doped multiwalls, Nano Lett., 5 (2005) 2465-2469.

[32] J.P. Paraknowitsch, A. Thomas, Doping carbons beyond nitrogen: an overview of advanced heteroatom doped carbons with boron, sulphur and phosphorus for energy applications, Energ. Environ. Sci., 6 (2013) 2839.

[33] Y. Wang, C.X. Guo, J. Liu, T. Chen, H. Yang, C.M. Li, $\mathrm{CeO}_{2}$ nanoparticles/graphene nanocomposite-based high performance supercapacitor, Dalton Trans, 40 (2011) 6388-6391.

[34] S.H. Aboutalebi, A.T. Chidembo, M. Salari, K. Konstantinov, D. Wexler, H.K. Liu, S.X. Dou, Comparison of GO, GO/MWCNTs composite and MWCNTs as potential electrode materials for supercapacitors, Energ. Environ. Sci., 4 (2011).

[35] B.E. Conway, V. Birss, J. Wojtowicz, The role and utilization of 
1

2

3

4

5

6

7

8

9

10

11

12

13

14

15

16

17

18

19

20

21

22

23

24

25

26

27

28

29

30

31

32

33

34

35

36

37

38

39

40

41

42

43

44

45

46

47

48

49

50

51

52

53

54

55

56

57

58

59

60

61

62

63

64

65

pseudocapacitance for energy storage by supercapacitors, J. Power Sources, 66 (1997) $1-14$. 


\section{Graphical Abstract}
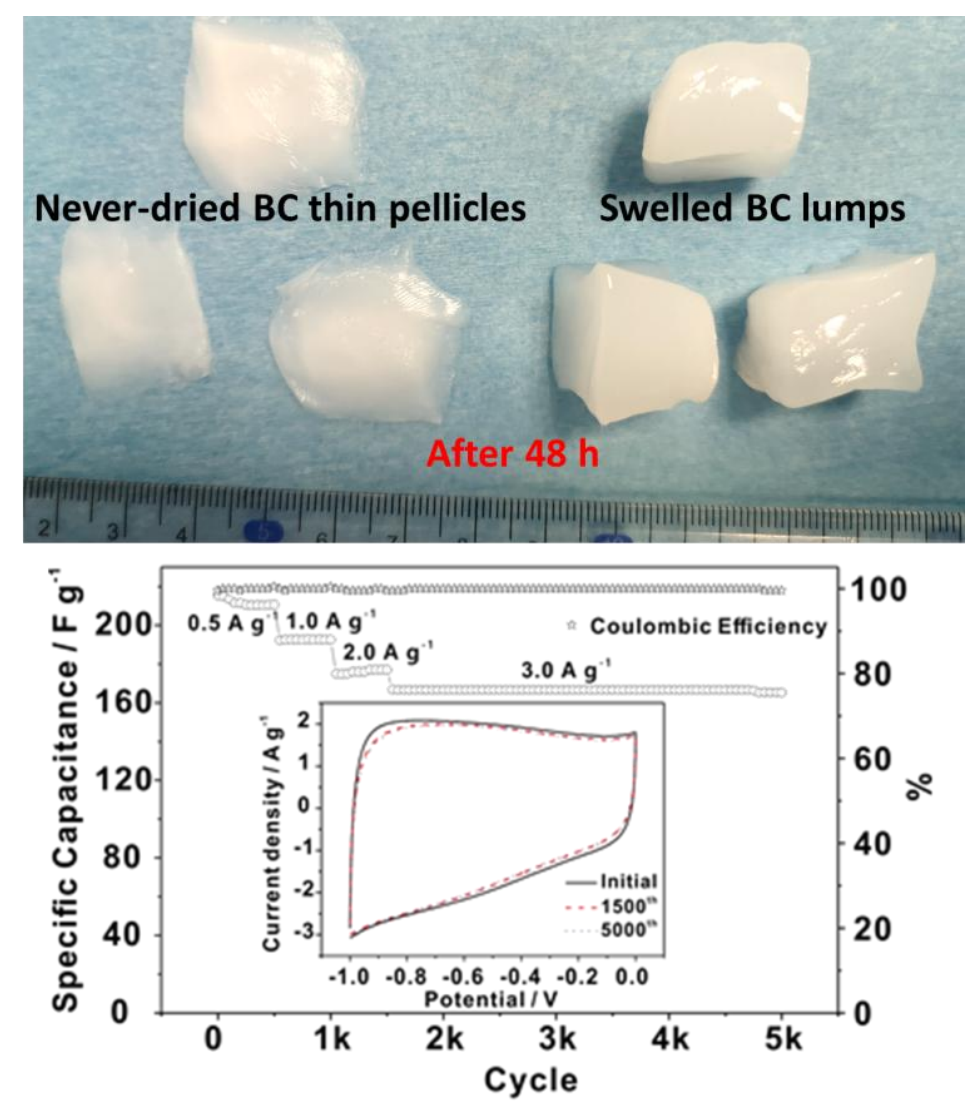

Three-dimensional nanofibrous NSCFs with a high N/S doping content (6.90 at\% for $\mathrm{N}$ and 1.02 at\% for $\mathrm{S}$ ) were obtained via an absorption-swelling strategy and subsequent heat treatment. 

Supplementary Material for on-line publication only
Click here to download Supplementary Material for c Click here to download Supplementary Material for on-line publication only: Supplementary information.doc 


\section{Figure}

Click here to download Figure: Figures.doc

\section{Figures}

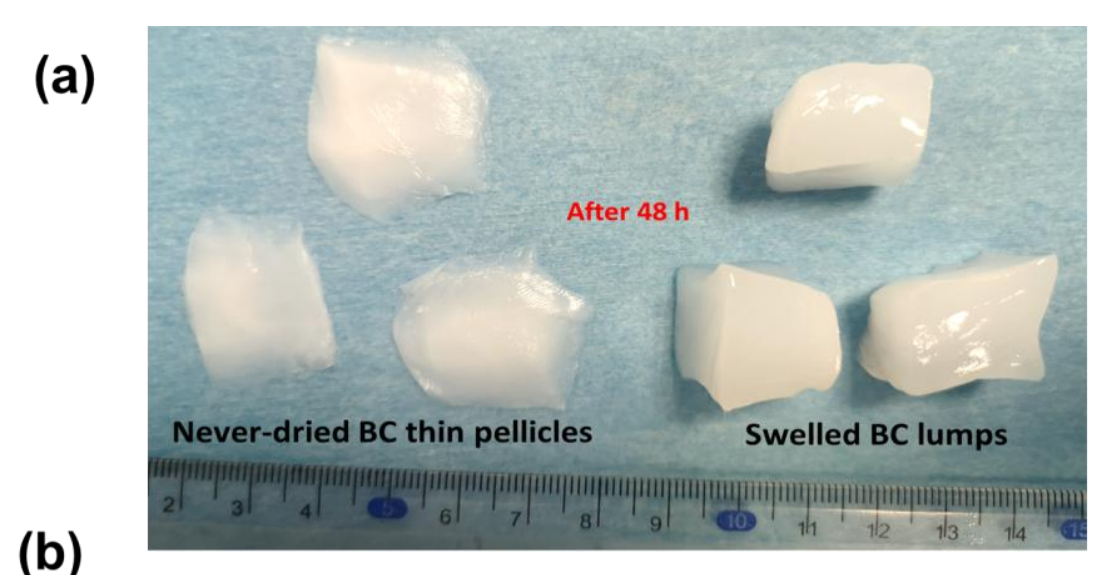

(b)

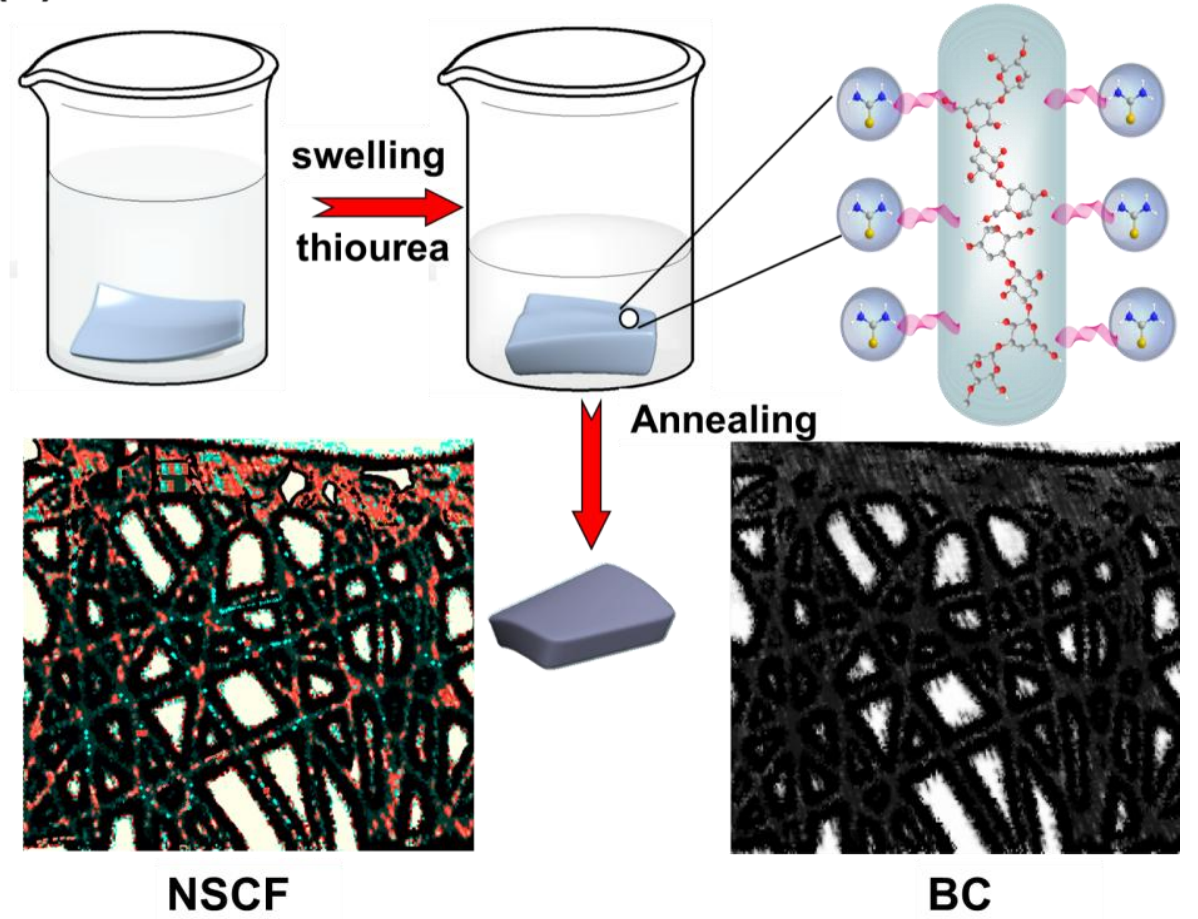

Figure 1 (a) Digital photograph of never-dried BC thin pellicles and the swelled BC pellicles after soaking in saturated thiourea aqueous solution for $48 \mathrm{~h}$. (b) Schematic illustration of the preparation process of NSCF. 

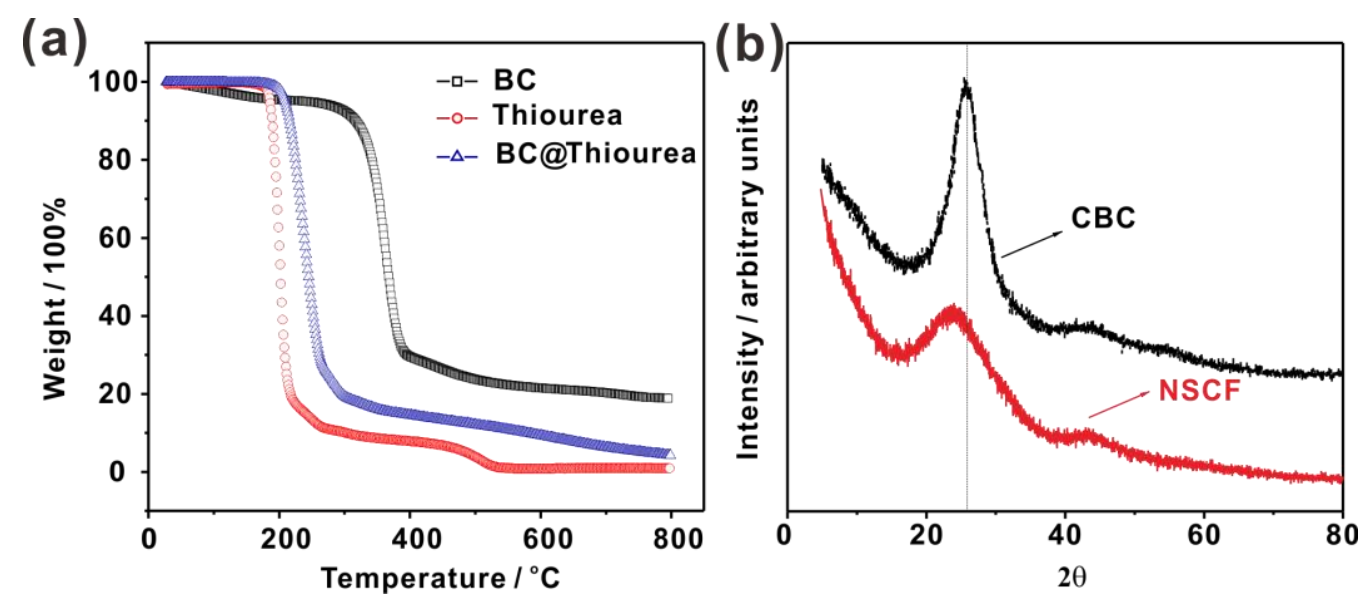

Figure 2 (a) TGA curves of BC, thiourea and BC@ thiourea composite. (b) XRD patterns of CBC and NSCF.
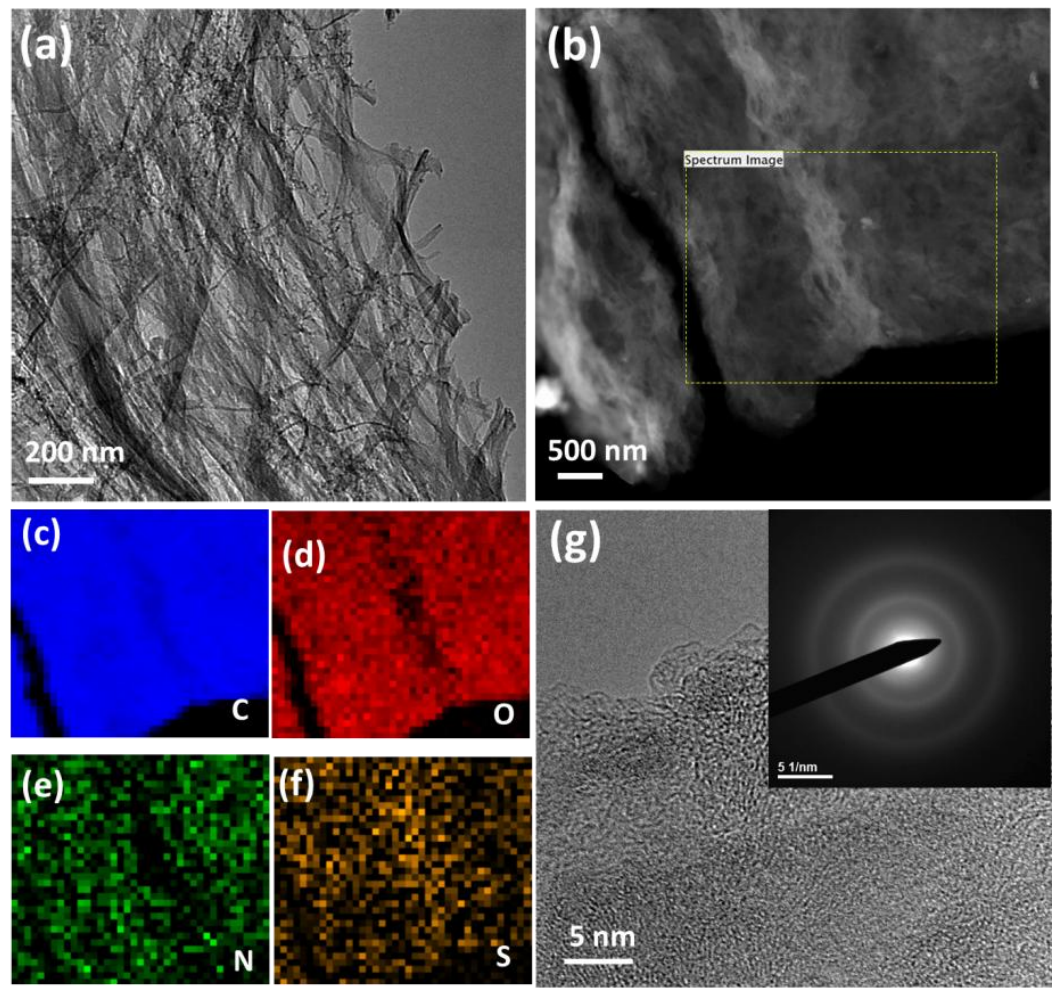

Figure 3 (a) TEM image of NSCF. S-TEM image (b) and corresponding EELS mapping images of NSCF: C (c), O (d), N (e) and S (f). (g) HR-TEM image of NSCF, inset shows its SAED pattern. 

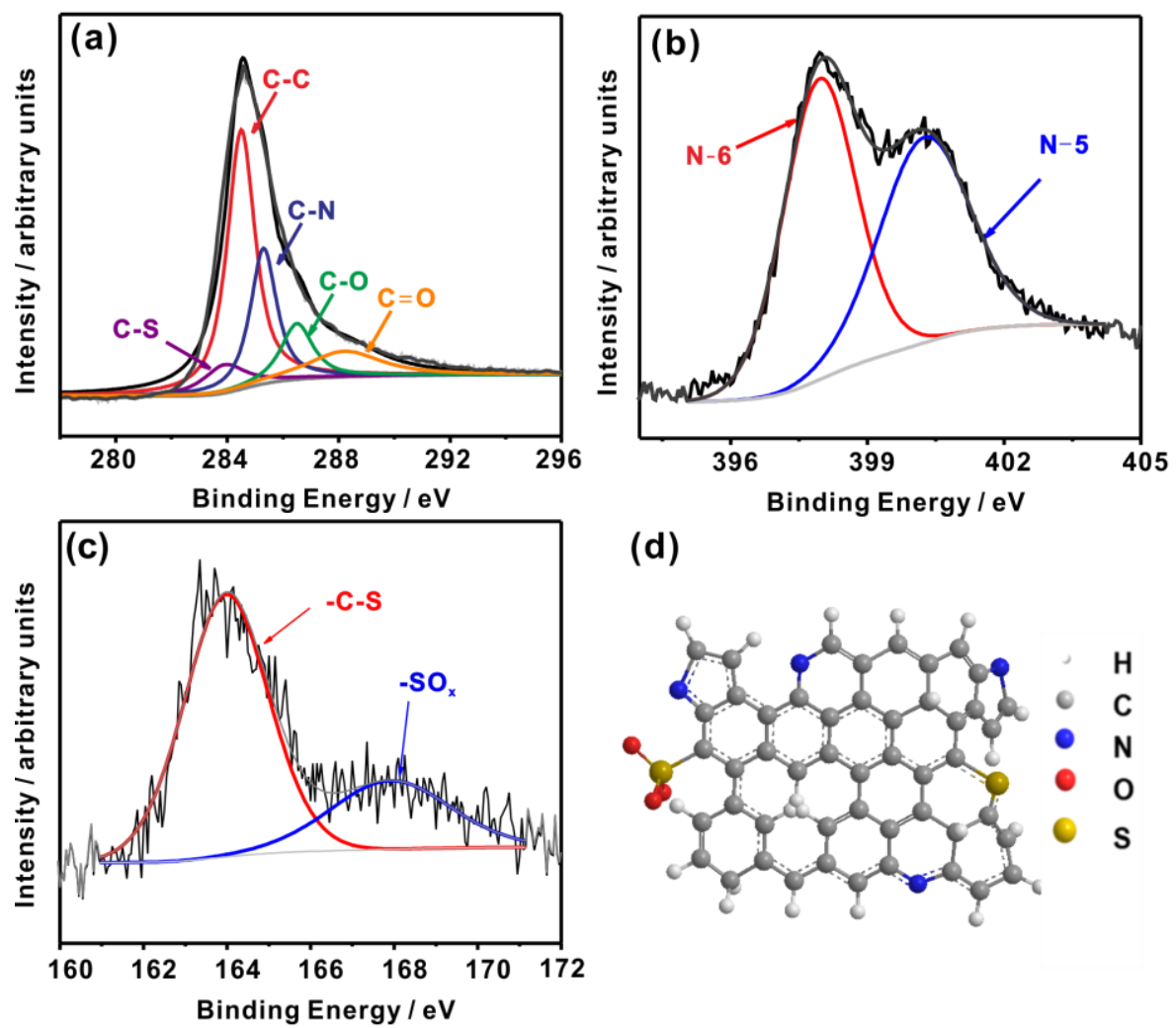

(d)

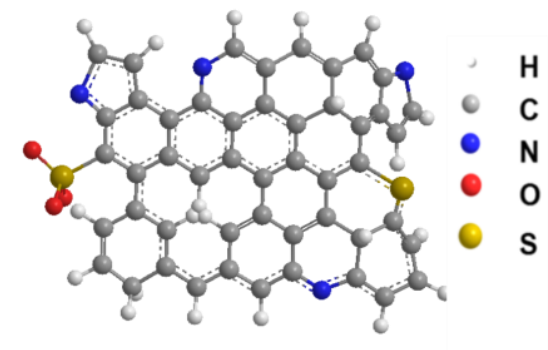

Figure 4 High-resolution XPS spectra of NSCF: C1s (a), N1s (b) and S2p (c). Schematic illustration of the molecular model of NSCF (d).

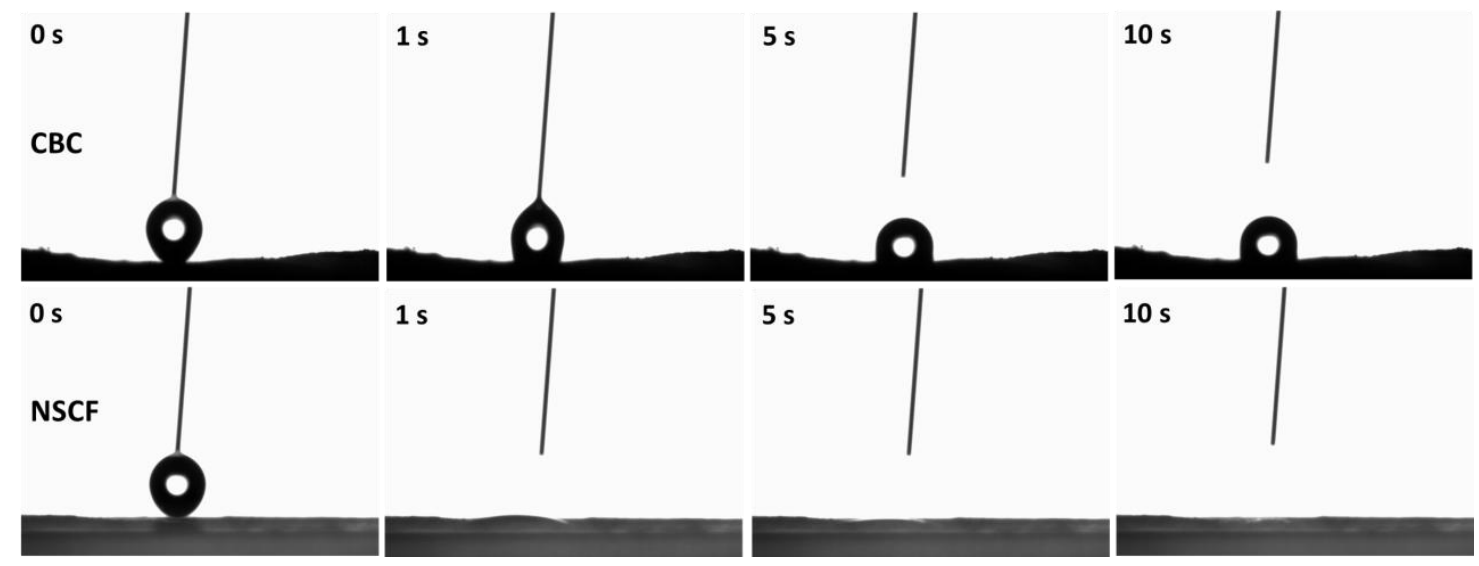

Figure 5 Water infiltration comparisons between CBC and NSCF. 
(a)
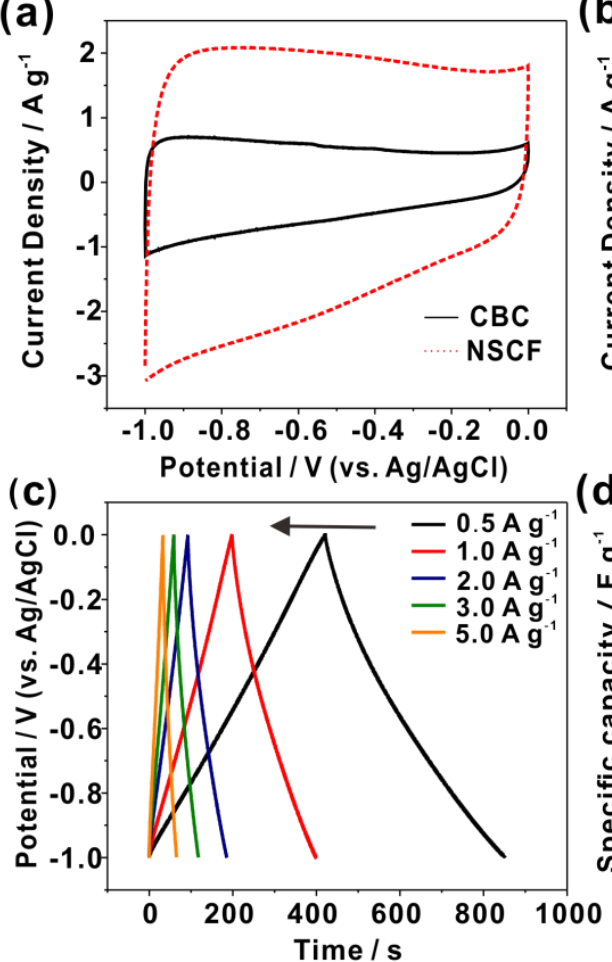

(b)
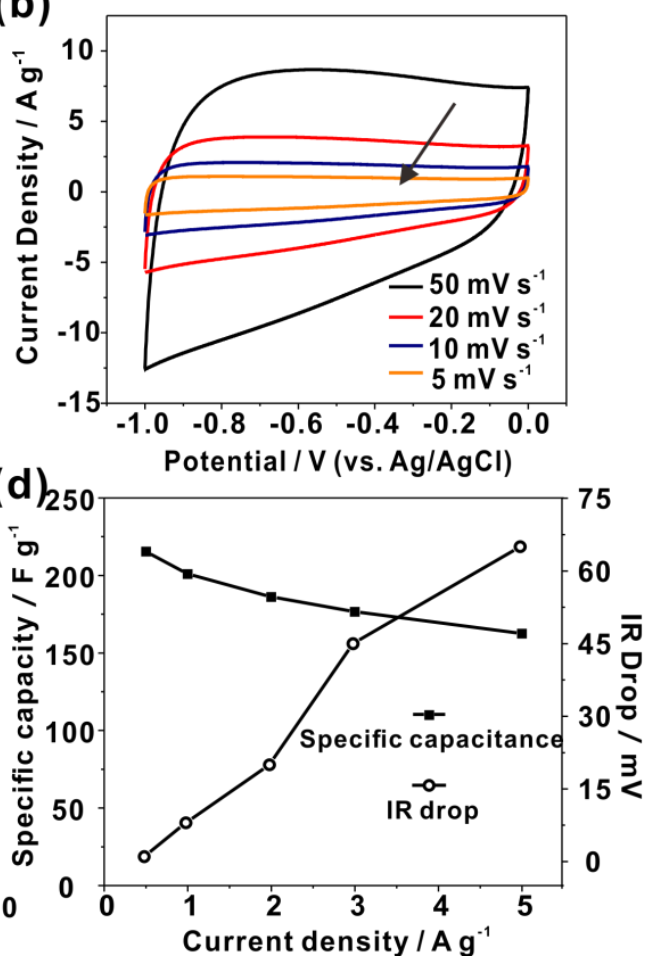

Figure 6 Comparison of CV curves between CBC and NSCF; (b) CV curves of NSCF at different scan rates; (c) GCD curves of NSCF at different current density; (d) Specific capacitance and IR drop values of NSCF at different current densities. 


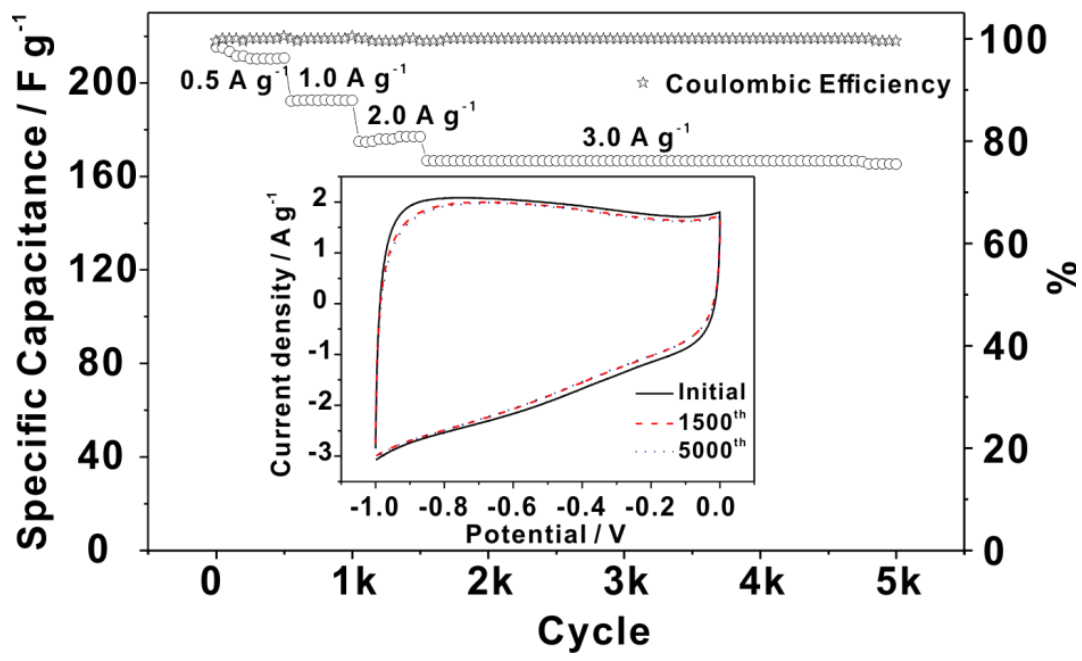

Figure 7 Cycling performance and Coulombic efficiency of NSCF. (Inset shows the corresponding $\mathrm{CV}$ curves during the cycling at a scan rate of $10 \mathrm{mV} \mathrm{s}^{-1}$ )
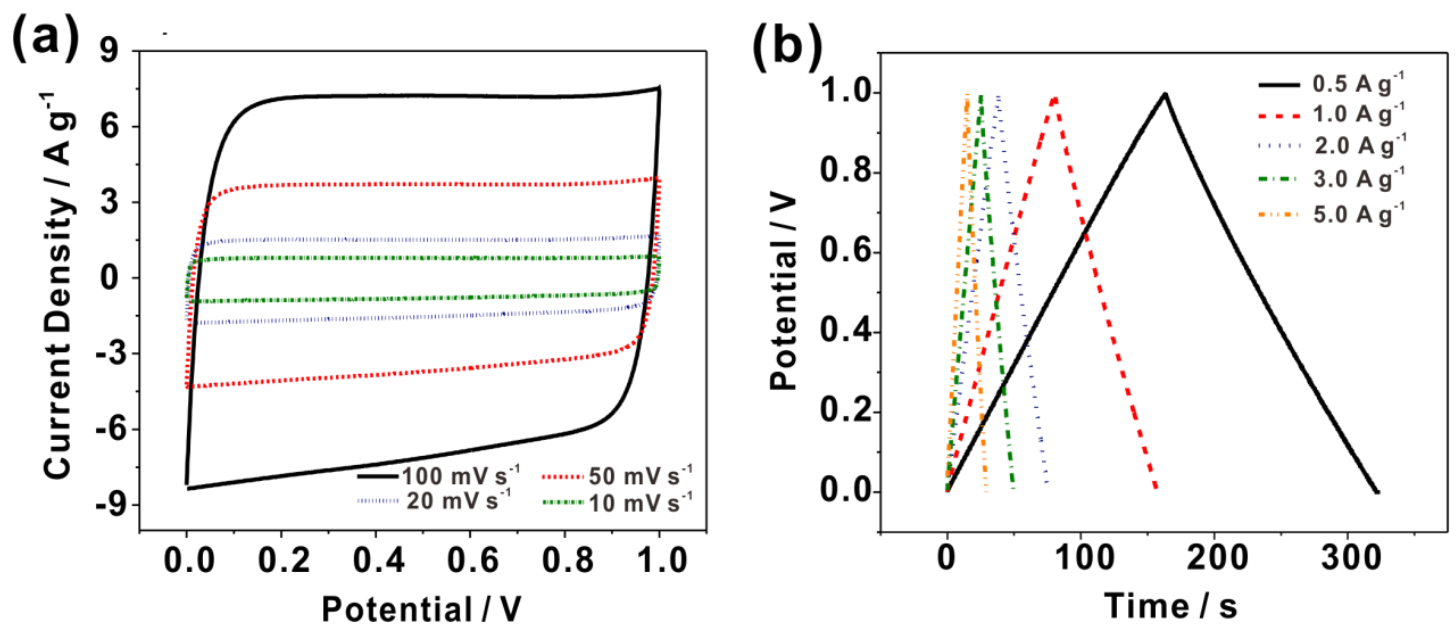

Figure 8 (a) CV curves of NSCF base device at different scan rates. (b) GCD curves of NSCF base device at different current densities. 

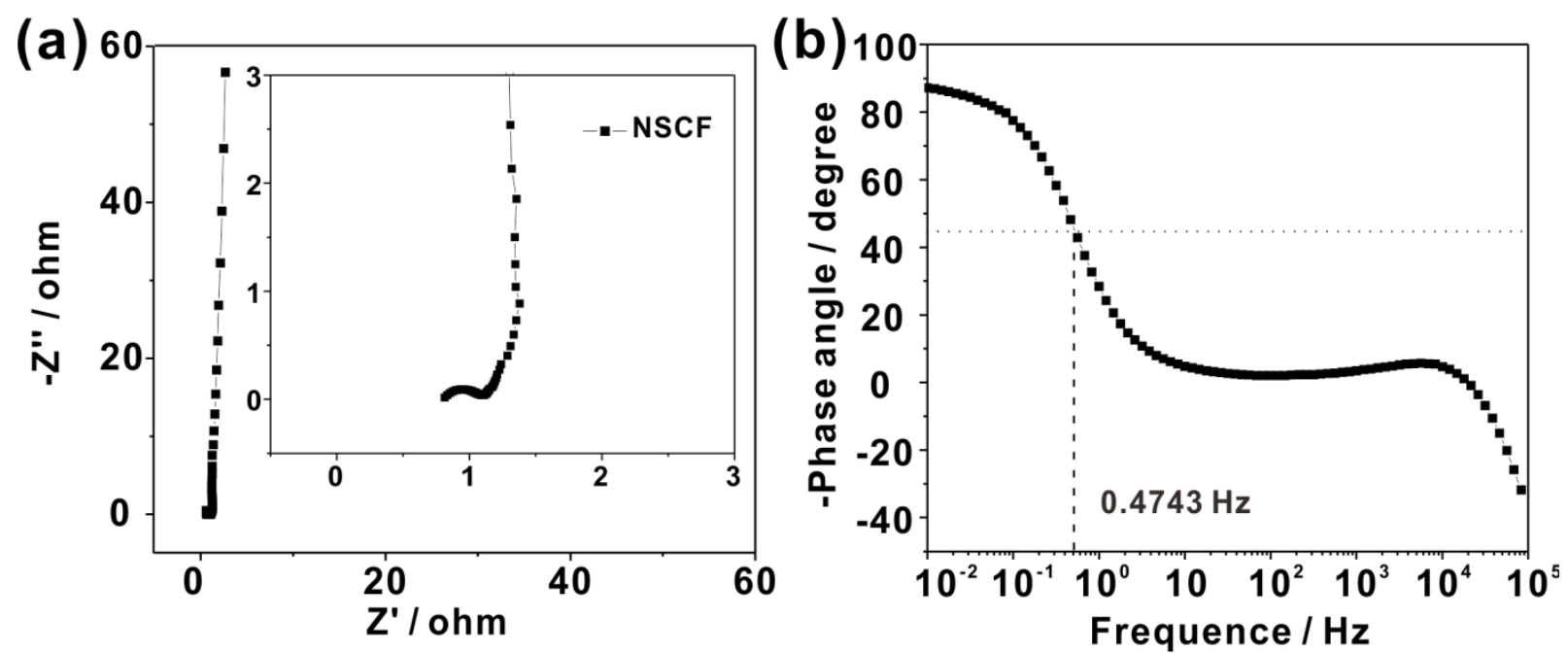

Figure 9 (a) Nyquist plots of the NSCF based device; (b) The corresponding plots of Frequency vs Phase angle. 